\title{
SYNERGISTIC EFFECTS OF FREQUENCY AND TEMPERATURE ON FATIGUE HYSTERESIS OF A CROSS-PLY SiC/MAS COMPOSITE UNDER TENSION-TENSION LOADING
}

\author{
LI LONGBIAO \\ College of Civil Aviation, Nanjing University of Aeronautics and Astronautics \\ No.29 Yudao St., Nanjing 210016, PR China \\ "E-mail: 1lb451@nuaa.edu.cn
}

Submitted July 18, 2018; accepted September 28, 2018

\begin{abstract}
Keywords: Ceramic-matrix composites (CMCs), Fatigue, Hysteresis loops, Hysteresis modulus, Interface shear stress
In this paper, the synergistic effects of the loading frequency and testing temperature on the fatigue hysteresis behaviour of a cross-ply SiC/MAS ceramic-matrix composite are investigated. The fatigue stress-strain hysteresis loop models, considering different matrix cracking modes, are developed to establish the relationships among the fatigue hysteresis loops, fatigue hysteresis dissipated energy and fibre/matrix interface shear stress. Comparing the experimental fatigue hysteresis dissipated energy with the theoretical values, the fibre/matrix interface shear stress of the cross-ply SiC/MAS composite under the loading frequency of 1 and $10 \mathrm{~Hz}$ at $566^{\circ} \mathrm{C}$ and $1093{ }^{\circ} \mathrm{C}$ in air conditions are obtained for different applied cycle numbers and fatigue peak stresses. At a low loading frequency of $1 \mathrm{~Hz}$, the fibre/matrix interface shear stress and interface shear stress degradation rate of the cross-ply SiC/MAS are higher than that at the loading frequency of $10 \mathrm{~Hz}$. At $1093{ }^{\circ} \mathrm{C}$ in air conditions, the fibre/matrix interface shear stress and interface shear stress degradation rate of the cross-ply SiC/MAS are higher than that at $566{ }^{\circ} \mathrm{C}$ in air conditions.
\end{abstract}

\section{INTRODUCTION}

Ceramics have excellent stiffness-to-weight and strength-to-weight ratios compared with traditional metals, especially at high temperature. However, their use as structural components is severely limited due to brittleness. The inherent brittleness of ceramics can be overcome by using fibre reinforcements, which can debond and slide through the matrix to dissipate energy. At the same time, the fibre-reinforced ceramic-matrix composites (CMCs) retain the attractive high temperature properties of ceramics [1].

In order to use fibre-reinforced CMCs with confidence, designers and engineers must be able to predict the mechanical response under cyclic fatigue loading. Upon unloading and subsequent reloading, when the peak stress exceeds the first matrix cracking stress, fatigue stress-strain hysteresis loops appear as fibres that slide relative to the matrix in the interface de-bonded region [2]. The shape, location and area of the fatigue stress-strain hysteresis loops can be used to reveal the internal damage evolution in the fibre-reinforced CMCs $[3,4]$. Li et al. $[5,6]$ investigated the cyclic loading/ unloading tensile and tension-tension fatigue behaviour of a unidirectional $\mathrm{C} / \mathrm{SiC}$ composite at room temperature and elevated temperatures. The stress-strain hysteresis loops corresponding to different fatigue peak stresses and applied cycle numbers have been predicted using fatigue hysteresis loops models considering different fibre/matrix interface slip cases. Under cyclic fatigue loading, the decrease in the interface shear stress is the main reason that fibre-reinforced CMCs suffer fatigue failure. Reynaud et al. [7, 8] investigated the fatigue hysteresis evolution of $2 \mathrm{D}$ woven $\mathrm{SiC} / \mathrm{SiC}$ and $2.5 \mathrm{D}$ woven $\mathrm{C} / \mathrm{SiC}$ at room temperature and elevated temperatures in an inert atmosphere. The fatigue stress-strain hysteresis loops area of the 2D woven $\mathrm{SiC} / \mathrm{SiC}$ composite increases with the test temperature and the applied cycle number; however, the fatigue stress-strain hysteresis loops area of the $2.5 \mathrm{D}$ woven $\mathrm{C} / \mathrm{SiC}$ decreases with test temperature and the applied cycles. The difference in the fatigue hysteresis loops area evolution with the applied cycle number between the $2 \mathrm{D}$ woven $\mathrm{SiC} / \mathrm{SiC}$ and the $2.5 \mathrm{D}$ woven $\mathrm{C} / \mathrm{SiC}$ is mainly due to the thermal residual stress that exists in the fibre/matrix interface. Fantozzi and Reynaud [9] investigated the fatigue hysteresis behaviour of bi- or multi-directional fibres reinforced CMCs at room temperature and elevated temperatures in an inert or in an oxidation atmosphere. The relationship between the internal friction evolution and the fibre/matrix interface shear stress has been established, which can be 
used to measure the evolution of the interface shear stress. Li [10-12] developed an approach to estimate the fibre/matrix interface shear stress of fibre-reinforced CMCs from the fatigue hysteresis loop area. The fibre/ matrix interface shear stress in a unidirectional, crossply, and $2.5 \mathrm{D} \mathrm{C} / \mathrm{SiC}$ at room temperature and $800{ }^{\circ} \mathrm{C}$ in air conditions has been estimated. The fibre/matrix interface shear stress degradation rate at $800{ }^{\circ} \mathrm{C}$ in air conditions is much higher than that at room temperature due to the interphase oxidation. However, in the research mentioned above, the synergistic effects of the loading frequency and testing temperature on the fatigue hysteresis behaviour of cross-ply CMCs have not been investigated.

In this paper, the synergistic effects of the loading frequency and testing temperature on the fatigue hysteresis behaviour of cross-ply $\mathrm{SiC} / \mathrm{MAS}$ composite are investigated. The damage evolution process under tension-tension cyclic fatigue loading is analysed using the fatigue hysteresis loops. Comparing the experimental fatigue hysteresis dissipated energy with the theoretical computational values, the fibre/matrix interface shear stress of a cross-ply $\mathrm{SiC} / \mathrm{MAS}$ at $566{ }^{\circ} \mathrm{C}$ and $1093{ }^{\circ} \mathrm{C}$ in air conditions under the loading frequency of 1 and $10 \mathrm{~Hz}$ are obtained corresponding to different applied cycle numbers and fatigue peak stresses.

\section{EXPERIMENTAL}

Nicalon $^{\mathrm{TM}} \mathrm{SiC}$ (Nippon Carbon Co., Ltd., Tokyo, Japan) fibre-reinforced barium-stuffed magnesium aluminosilicate (MAS) cordierite matrix composite ( $\mathrm{SiC} /$ MAS CMCs) was provided by Steiner [13]. The fibres have an average diameter of $15 \mu \mathrm{m}$. The cross-ply SiC/ MAS composite was manufactured by hot pressing at temperature above $1200{ }^{\circ} \mathrm{C}$. The volume fraction of the fibres was approximately $40 \%$. The specimens, with dimensions of $153 \times 5.08 \times 3.175 \mathrm{~mm}$, were cut from the square composite plates.

Tension-tension fatigue tests were conducted on an MTS servo hydraulic load-frame (MTS Systems Corp., Minneapolis MN, USA). The longitudinal deformation was measured with the aid of an MTS 632.65B-03 extensometer with quartz rods. The rods were sharpened and the extensometer calibrated to a gauge length of $25.4 \mathrm{~mm}$ prior to each of the tests. The tension-tension fatigue tests at $566^{\circ} \mathrm{C}$ and $1093^{\circ} \mathrm{C}$ in air were performed under a load control with a triangular waveform and a loading frequency of 1 and $10 \mathrm{~Hz}$ and the fatigue load ratio, i.e., minimum to maximum stress, of 0.1 , and the maximum number of applied cycles was defined to be 1000000 applied cycles. During cyclic fatigue loading, the fatigue hysteresis modulus $\mathrm{E}_{\mathrm{a}}$ is calculated by Equation 1. [3]

$$
E_{a}=\frac{\sigma_{\max }-\sigma_{\min }}{\varepsilon_{\max }-\varepsilon_{\min }}
$$

where $\sigma_{\max }$ and $\sigma_{\min }$ denote the fatigue peak and valley stresses, respectively; and $\varepsilon_{\max }$ and $\varepsilon_{\min }$ denote the fatigue peak and valley strains, respectively.

The tensile strength of SiC/MAS at $566{ }^{\circ} \mathrm{C}$ in air was $292 \mathrm{MPa}$. The fatigue peak stresses were $137 \mathrm{MPa}$ $\left(47.1 \% \sigma_{\text {UTS }}\right), 120 \mathrm{MPa}\left(41.2 \% \sigma_{\text {UTS }}\right), 103 \mathrm{MPa}(35.3 \%$ $\left.\sigma_{\text {UtS }}\right), 98 \mathrm{MPa}\left(33.6 \% \sigma_{\text {UtS }}\right)$ and $86 \mathrm{MPa}\left(29.4 \% \sigma_{\text {UTS }}\right)$ at the loading frequency of $10 \mathrm{~Hz}$, and $137 \mathrm{MPa}(47.1 \%$ $\left.\sigma_{\text {UTS }}\right), 120 \mathrm{MPa}\left(41.2 \% \sigma_{\text {UTS }}\right), 103 \mathrm{MPa}\left(35.3 \% \sigma_{\mathrm{UTS}}\right)$, and $99 \mathrm{MPa}\left(34.2 \% \sigma_{\mathrm{UTS}}\right)$ at the loading frequency of $1 \mathrm{~Hz}$. The fatigue life $\mathrm{S}-\mathrm{N}$ curve of $\mathrm{SiC} / \mathrm{MAS}$ at $566^{\circ} \mathrm{C}$ in air is illustrated in Figure 1.

The tensile strength of SiC/MAS at $1093{ }^{\circ} \mathrm{C}$ in air was $209 \mathrm{MPa}$. The fatigue peak stresses were $137 \mathrm{MPa}$ $\left(65.8 \% \sigma_{\mathrm{UTS}}\right), 103 \mathrm{MPa}\left(49.4 \% \sigma_{\mathrm{UTS}}\right), 96 \mathrm{MPa}(46.1 \%$ $\left.\sigma_{\text {UTS }}\right), 94 \mathrm{MPa}\left(45.3 \% \sigma_{\text {UTS }}\right)$ and $86 \mathrm{MPa}\left(41.1 \% \sigma_{\text {UTS }}\right)$ at the loading frequency of $10 \mathrm{~Hz}$, and $137 \mathrm{MPa}(65.8 \%$ $\left.\sigma_{\text {UTS }}\right), 120 \mathrm{MPa}\left(57.6 \% \sigma_{\text {UTS }}\right), 103 \mathrm{MPa}\left(49.4 \% \sigma_{\text {UTS }}\right)$, $96 \mathrm{MPa}\left(46.1 \% \sigma_{\mathrm{UTS}}\right)$, and $86 \mathrm{MPa}\left(41.1 \% \sigma_{\mathrm{UTS}}\right)$ at the loading frequency of $1 \mathrm{~Hz}$. The fatigue life $\mathrm{S}-\mathrm{N}$ curve of $\mathrm{SiC} / \mathrm{MAS}$ at $1093{ }^{\circ} \mathrm{C}$ in air is illustrated in Figure 2.

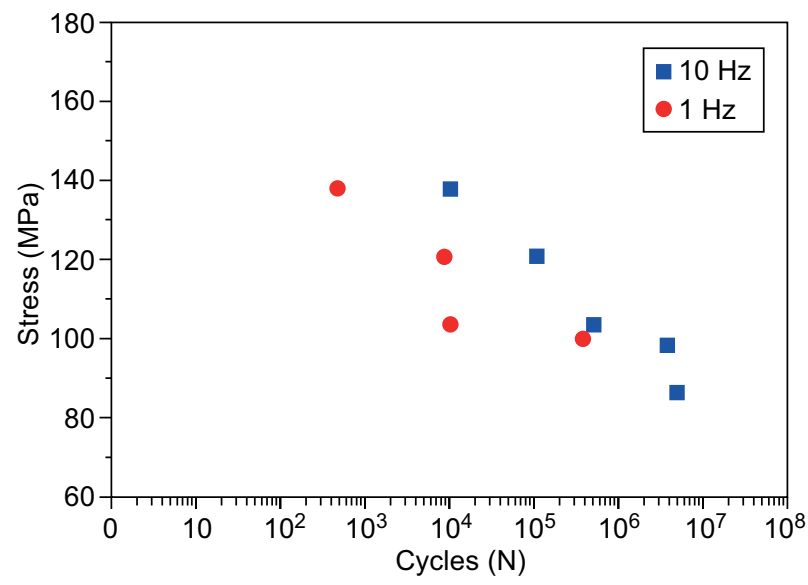

Figure 1. The fatigue life of the $\mathrm{S}-\mathrm{N}$ curve of the cross-ply SiC/ MAS composite at $566^{\circ} \mathrm{C}$ in air.

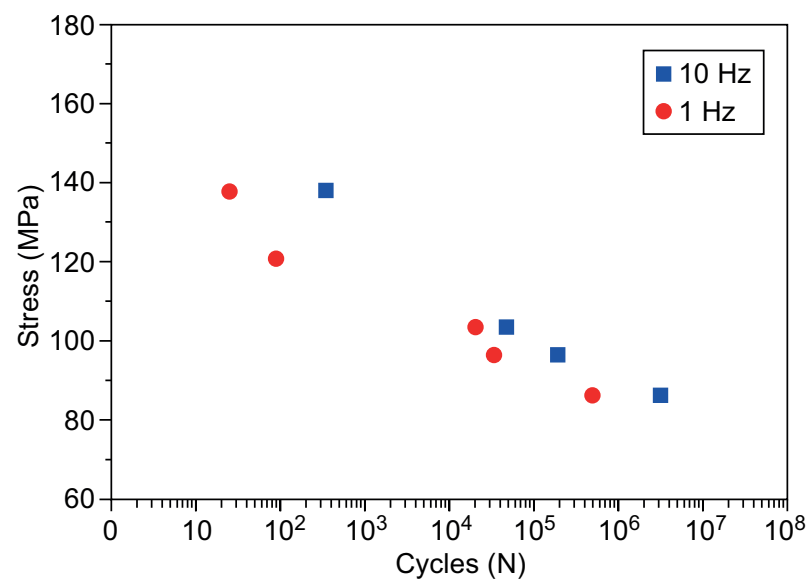

Figure 2. The fatigue life of the S-N curve of the cross-ply SiC/ MAS composite at $1093{ }^{\circ} \mathrm{C}$ in air. 


\section{EXPERIMENTAL RESULTS}

\section{$\mathrm{SiC} / \mathrm{MAS}$ at $566^{\circ} \mathrm{C}$ in air}

The experimental fatigue hysteresis modulus and fatigue hysteresis dissipated energy versus the applied cycle number curves of the cross-ply SiC/MAS composite at $566{ }^{\circ} \mathrm{C}$ in air conditions are illustrated in Figures 3 and 4.

At the loading frequency of $1 \mathrm{~Hz}$, when the fatigue peak stress is $\sigma_{\max }=137 \mathrm{MPa}$, the fatigue hysteresis modulus decreases from $117 \mathrm{GPa}$ at the $1^{\text {st }}$ applied cycle to $73 \mathrm{GPa}$ at the $50^{\text {th }}$ applied cycle, due to the formation and propagation of matrix cracking in the $90^{\circ}$ and $0^{\circ}$ plies, as shown in Figure 3a; and the fatigue hysteresis dissipated energy decreases from $5.3 \mathrm{~kJ} \cdot \mathrm{m}^{-3}$ at the $4^{\text {th }}$ applied cycle to $4.4 \mathrm{~kJ} \cdot \mathrm{m}^{-3}$ at the $230^{\text {th }}$ applied cycle, due to the matrix cracking and interface oxidation in the $0^{\circ}$ plies, as shown in Figure 4a. When the fatigue peak stress is $\sigma_{\max }=120 \mathrm{MPa}$, the fatigue hysteresis modulus decreases from $117 \mathrm{GPa}$ at the $1^{\text {st }}$ applied cycle to $83 \mathrm{GPa}$ at the $110^{\text {th }}$ applied cycle, as shown in Figure 3a; and the fatigue hysteresis dissipated energy decreases from $4.5 \mathrm{~kJ} \cdot \mathrm{m}^{-3}$ at the $3^{\text {rd }}$ applied cycle to $3.2 \mathrm{~kJ} \cdot \mathrm{m}^{-3}$ at the $105^{\text {th }}$ applied cycle, as shown in Figure 4a. When the fatigue peak stress is $\sigma_{\max }=103 \mathrm{MPa}$, the fatigue hysteresis modulus decreases from $117 \mathrm{GPa}$ at the 1st applied cycle to $104 \mathrm{GPa}$ at the $150^{\text {th }}$ applied cycle, as shown in Figure 3a; and the fatigue hysteresis dissipated energy decreases from $2.8 \mathrm{~kJ} \cdot \mathrm{m}^{-3}$ at the $4^{\text {th }}$ applied cycle to $2.4 \mathrm{~kJ} \cdot \mathrm{m}^{-3}$ at the $920^{\text {th }}$ applied cycle, as shown in Figure 4a.

At the loading frequency of $10 \mathrm{~Hz}$, when the fatigue peak stress is $\sigma_{\max }=137 \mathrm{MPa}$, the fatigue hysteresis modulus decreases from $117 \mathrm{GPa}$ at the $1^{\text {st }}$ applied cycle to $78 \mathrm{GPa}$ at the $110^{\text {th }}$ applied cycle, as shown in Figure 3b; and the fatigue hysteresis dissipated energy decreases from $6.5 \mathrm{~kJ} \cdot \mathrm{m}^{-3}$ at the $2^{\text {nd }}$ applied cycle to $3.6 \mathrm{~kJ} \cdot \mathrm{m}^{-3}$ at the $7730^{\text {th }}$ applied cycle, as shown in Figure

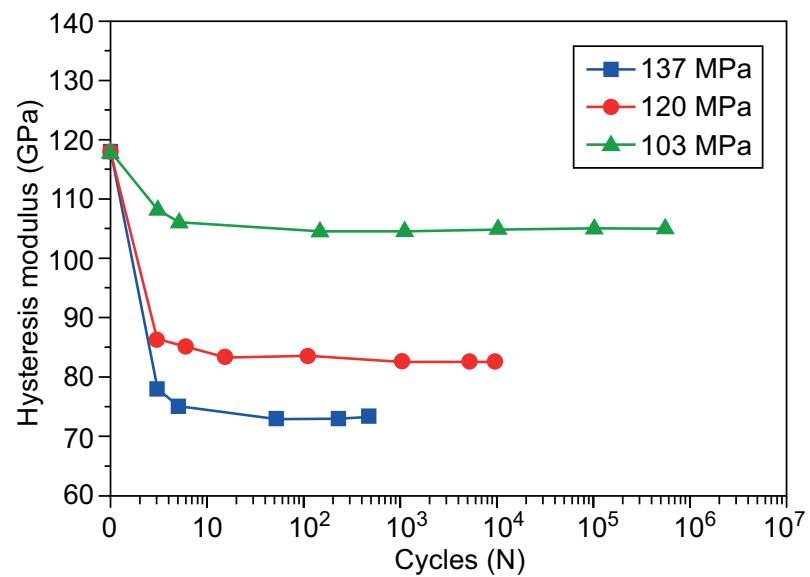

a)

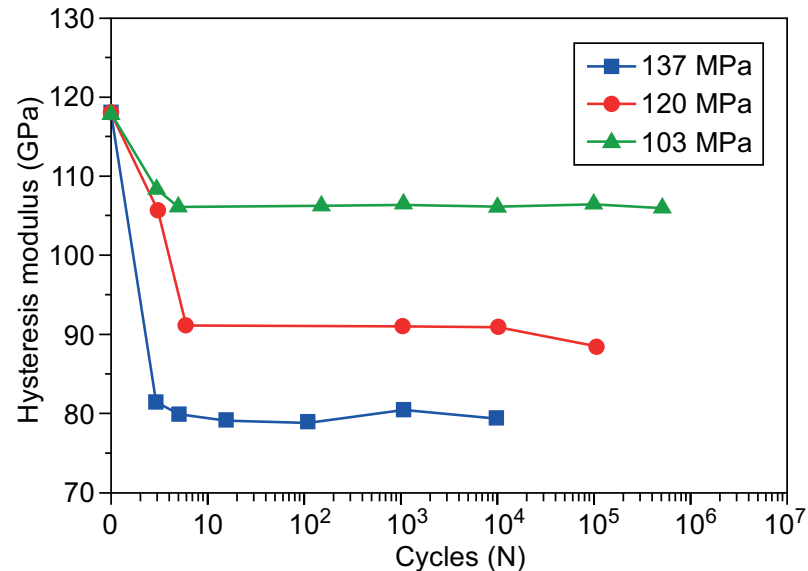

b)

Figure 3. The hysteresis modulus versus the cycle number curves of the cross-ply SiC/MAS composite at $566{ }^{\circ} \mathrm{C}$ in air corresponding to the loading frequency of: a) $1 \mathrm{~Hz}$; and b) $10 \mathrm{~Hz}$.

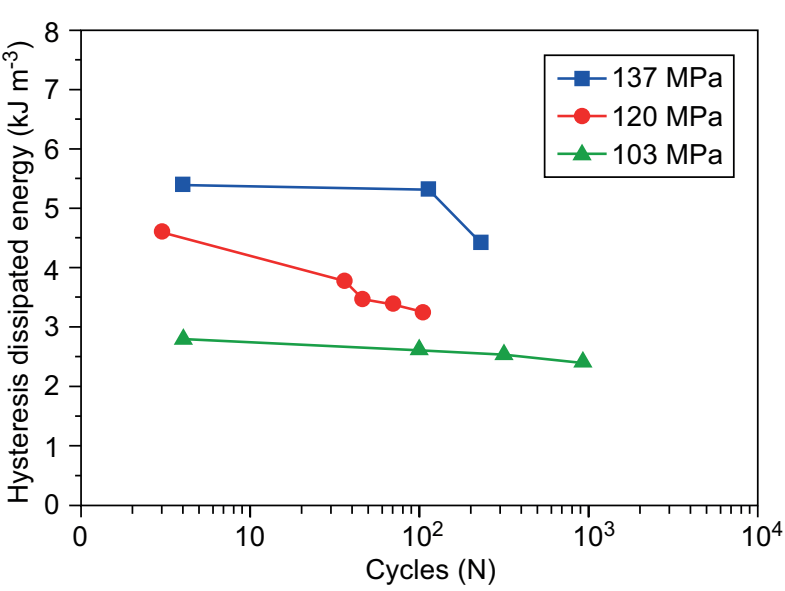

a)

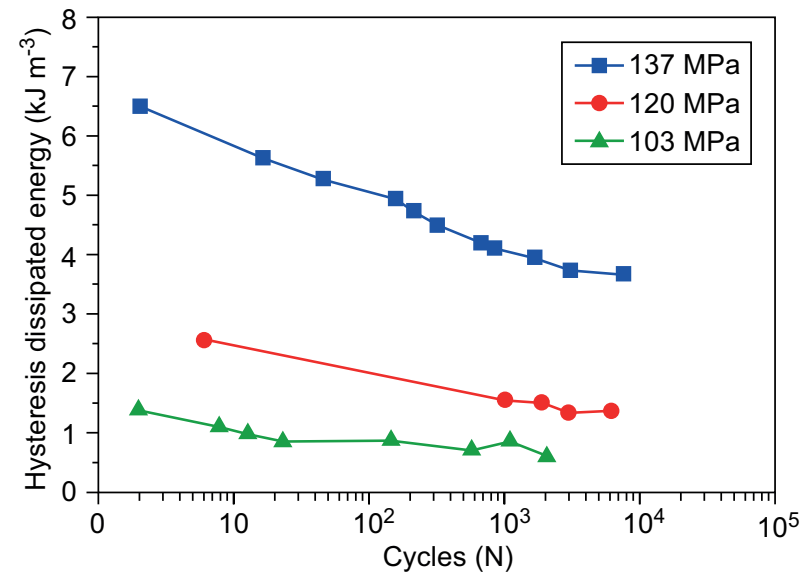

b)

Figure 4. The hysteresis dissipated energy versus the cycle number curves of the cross-ply SiC/MAS composite at $566{ }^{\circ} \mathrm{C}$ in air corresponding to the loading frequency of: a) $1 \mathrm{~Hz}$; and b) $10 \mathrm{~Hz}$. 
4b. When the fatigue peak stress is $\sigma_{\max }=120 \mathrm{MPa}$, the fatigue hysteresis modulus decreases from $117 \mathrm{GPa}$ at the $1^{\text {st }}$ applied cycle to $91 \mathrm{GPa}$ at the $1048^{\text {th }}$ applied cycle, as shown in Figure 3b; and the fatigue hysteresis dissipated energy decreases from $2.5 \mathrm{~kJ} \cdot \mathrm{m}^{-3}$ at the $6^{\text {th }}$ applied cycle to $1.3 \mathrm{~kJ} \cdot \mathrm{m}^{-3}$ at the 6150 th applied cycle, as shown in Figure $4 \mathrm{~b}$. When the fatigue peak stress is $\sigma_{\max }=103 \mathrm{MPa}$, the fatigue hysteresis modulus decreases from $117 \mathrm{GPa}$ at the $1^{\text {st }}$ applied cycle to $106 \mathrm{GPa}$ at the $150^{\text {th }}$ applied cycle, as shown in Figure $3 \mathrm{~b}$; and the fatigue hysteresis dissipated energy decreases from $1.3 \mathrm{~kJ} \cdot \mathrm{m}^{-3}$ at the $2^{\text {nd }}$ applied cycle to $0.6 \mathrm{~kJ} \cdot \mathrm{m}^{-3}$ at the $2073^{\text {th }}$ applied cycle, as shown in Figure $4 \mathrm{~b}$.

\section{$\mathrm{SiC} / \mathrm{MAS}$ at $1093{ }^{\circ} \mathrm{C}$ in air}

The experimental fatigue hysteresis modulus and fatigue hysteresis dissipated energy versus the cycle number curves of the cross-ply $\mathrm{SiC} / \mathrm{MAS}$ composite at $1093{ }^{\circ} \mathrm{C}$ in air conditions are illustrated in Figures 5 and 6.

At the loading frequency of $1 \mathrm{~Hz}$, when the fatigue peak stress is $\sigma_{\max }=137 \mathrm{MPa}$, the fatigue hysteresis modulus decreases from $96 \mathrm{GPa}$ at the $1^{\text {st }}$ applied cycle to $49 \mathrm{GPa}$ at the $10^{\text {th }}$ applied cycle, as shown in Figure 5a; and the fatigue hysteresis dissipated energy decreases from $43 \mathrm{~kJ} \cdot \mathrm{m}^{-3}$ at the $4^{\text {th }}$ applied cycle to $32 \mathrm{~kJ} \cdot \mathrm{m}^{-3}$ at the $25^{\text {th }}$ applied cycle, as shown in Figure $6 \mathrm{a}$. When the fatigue peak stress is $\sigma_{\max }=120 \mathrm{MPa}$, the fatigue hysteresis modulus decreases from $96 \mathrm{GPa}$ at the $1^{\text {st }}$ applied cycle to $53 \mathrm{GPa}$ at the $90^{\text {th }}$ applied cycle, as shown in Figure 5a; and the fatigue hysteresis dissipated energy decreases from $34 \mathrm{~kJ} \cdot \mathrm{m}^{-3}$ at the $3^{\text {rd }}$ applied cycle to $22 \mathrm{~kJ} \cdot \mathrm{m}^{-3}$ at the $75^{\text {th }}$ applied cycle, as shown in Figure $6 \mathrm{a}$. When the fatigue peak stress is $\sigma_{\max }=103 \mathrm{MPa}$, the fatigue hysteresis modulus decreases from $96 \mathrm{GPa}$ at the $1^{\text {st }}$ applied cycle to $63 \mathrm{GPa}$ at the $1013^{\text {rd }}$ applied cycle, as shown in Figure 5a; and the fatigue hysteresis dissipated

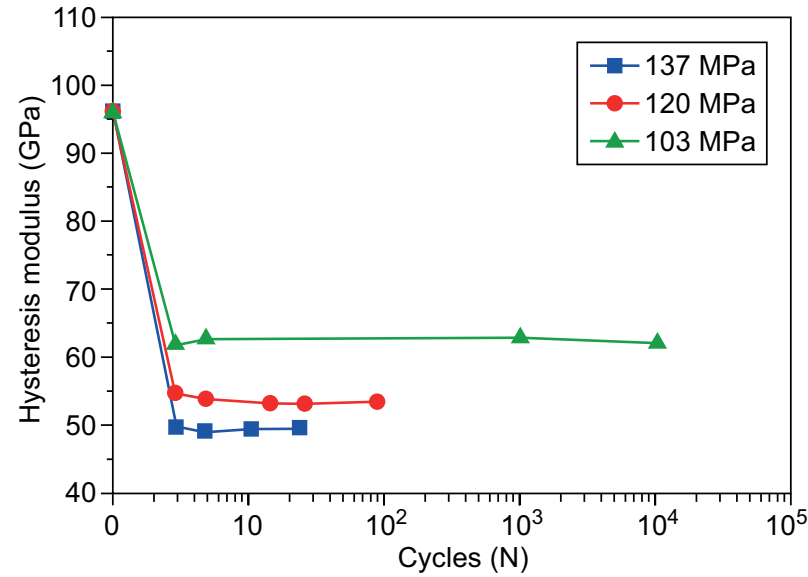

a)

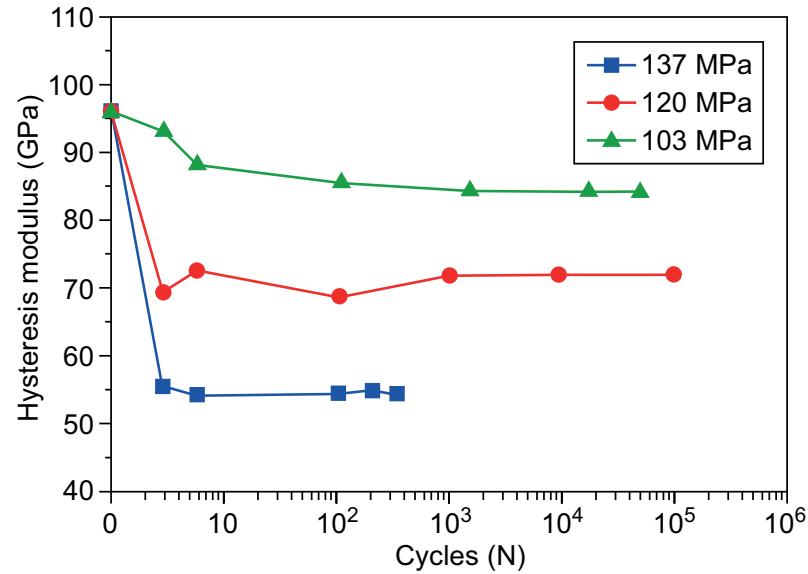

b)

Figure 5. The hysteresis modulus versus the cycle number curves of the cross-ply SiC/MAS composite at $1093{ }^{\circ} \mathrm{C}$ in air corresponding to the loading frequency of: a) $1 \mathrm{~Hz}$; and b) $10 \mathrm{~Hz}$.

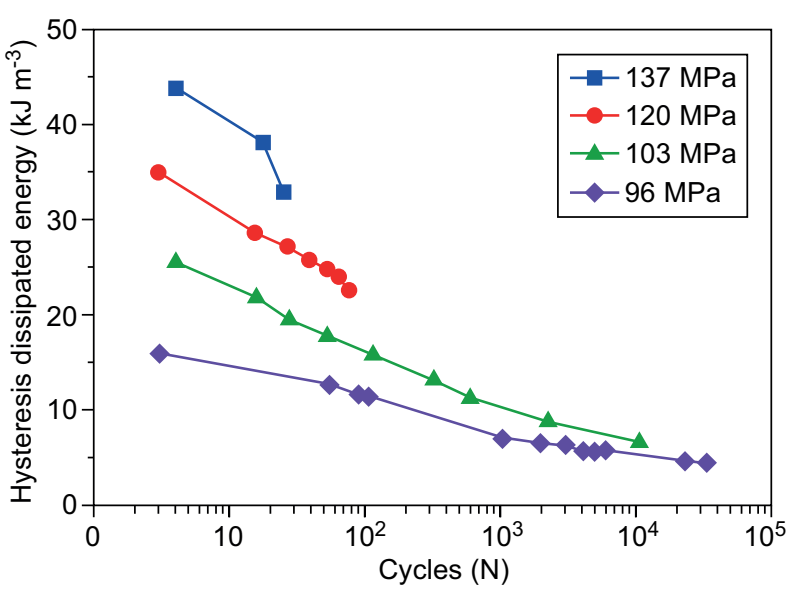

a)

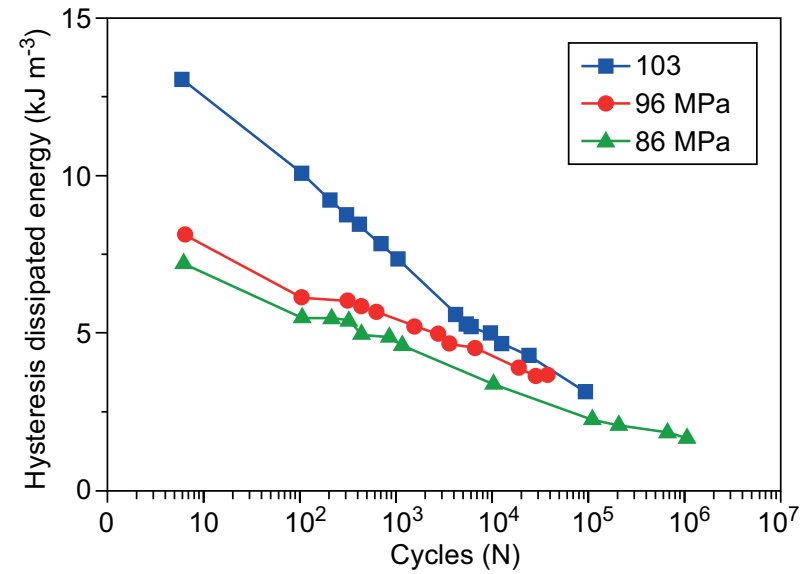

b)

Figure 6. The hysteresis dissipated energy versus the cycle number curves of the cross-ply SiC/MAS composite at $1093{ }^{\circ} \mathrm{C}$ in air corresponding to the loading frequency of: a) $1 \mathrm{~Hz}$; and b) $10 \mathrm{~Hz}$. 
energy decreases from $25 \mathrm{~kJ} \cdot \mathrm{m}^{-3}$ at the $4^{\text {th }}$ applied cycle to $6.5 \mathrm{~kJ} \cdot \mathrm{m}^{-3}$ at the $10608^{\text {th }}$ applied cycle, as shown in Figure 6a. When the fatigue peak stress is $\sigma_{\max }=96 \mathrm{MPa}$, the fatigue hysteresis dissipated energy decreases from $16 \mathrm{~kJ} \cdot \mathrm{m}^{-3}$ at the $3^{\text {rd }}$ applied cycle to $4.4 \mathrm{~kJ} \cdot \mathrm{m}^{-3}$ at the $33299^{\text {th }}$ applied cycle, as shown in Figure $6 \mathrm{a}$.

At the loading frequency of $10 \mathrm{~Hz}$, when the fatigue peak stress is $\sigma_{\max }=137 \mathrm{MPa}$, the fatigue hysteresis modulus decreases from $96 \mathrm{GPa}$ at the $1^{\text {st }}$ applied cycle to $54 \mathrm{GPa}$ at the $106^{\text {th }}$ applied cycle, as shown in Figure $5 \mathrm{~b}$. When the fatigue peak stress is $\sigma_{\max }=103 \mathrm{MPa}$, the fatigue hysteresis modulus decreases from $96 \mathrm{GPa}$ at the $1^{\text {st }}$ applied cycle to $68 \mathrm{GPa}$ at the $110^{\text {th }}$ applied cycle, as shown in Figure 5b; and the fatigue hysteresis dissipated energy decreases from $13 \mathrm{~kJ} \cdot \mathrm{m}^{-3}$ at the $6^{\text {th }}$ applied cycle to $3.1 \mathrm{~kJ} \cdot \mathrm{m}^{-3}$ at the $94044^{\text {th }}$ applied cycle, as shown in Figure 6b. When the fatigue peak stress is $\sigma_{\max }=96 \mathrm{MPa}$, the fatigue hysteresis modulus decreases from $96 \mathrm{GPa}$ at the $1^{\text {st }}$ applied cycle to $85 \mathrm{GPa}$ at the $110^{\text {th }}$ applied cycle, as shown in Figure $5 \mathrm{~b}$; and the fatigue hysteresis dissipated energy decreases from $8.1 \mathrm{~kJ} \cdot \mathrm{m}^{-3}$ at the $6^{\text {th }}$ applied cycle to $3.6 \mathrm{~kJ} \mathrm{~m}^{-3}$ at the $37439^{\text {th }}$ applied cycle, as shown in Figure $6 \mathrm{~b}$. When the fatigue peak stress is $\sigma_{\max }=86 \mathrm{MPa}$, the fatigue hysteresis dissipated energy decreases from $7.2 \mathrm{~kJ} \cdot \mathrm{m}^{-3}$ at the $6^{\text {th }}$ applied cycle to $1.6 \mathrm{~kJ} \cdot \mathrm{m}^{-3}$ at the $1063330^{\text {th }}$ applied cycle, as shown in Figure $6 \mathrm{~b}$.

\section{HYSTERESIS THEORIES}

Upon the first loading onto the fatigue peak stress $\sigma_{\max }$, which is higher than the first cracking stress of the transverse and longitudinal plies, it is assumed that the transverse cracks and matrix cracks would extend throughout the entire laminate cross-section. The multi-cracking modes in the cross-ply CMCs can be classified into five different modes, as shown in Figure 7, including: [14]

- Cracking mode I: transverse cracking in the transverse tow, with debonding at the ply boundary;

- Cracking mode II: transverse cracking and matrix cracking with perfect fibre/matrix bonding, and fracture of the fibres occurs in the longitudinal ply;

- Cracking mode III: transverse cracking and matrix cracking with fibre/matrix debonding and sliding in the longitudinal ply;

- Cracking mode IV: matrix cracking with perfect fibre/matrix bonding, and fracture of the fibres occurs in the longitudinal ply;

- Cracking mode V: matrix cracking and fibre/matrix interface debonding and sliding in the longitudinal ply.

The fatigue stress-strain hysteresis loops develop as a result of the energy dissipation through the frictional sliding between the fibres and the matrix upon unloading and subsequent reloading. In the matrix cracking modes mentioned above, the fibre/matrix interface debonding and sliding occur in the matrix cracking mode III and mode V. The shape, location and area of the hysteresis loops of the cross-ply CMCs depend on the fibre/matrix interface debonding and sliding state in the matrix cracking mode III and mode $\mathrm{V}$. The schematic figure for the fibre sliding relative to the matrix upon unloading and reloading is shown in

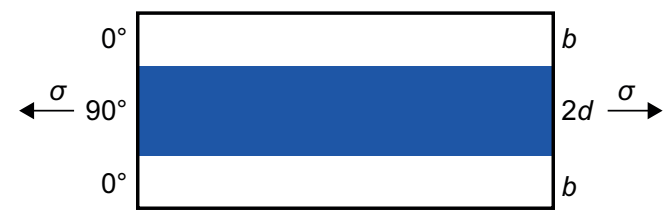

a)

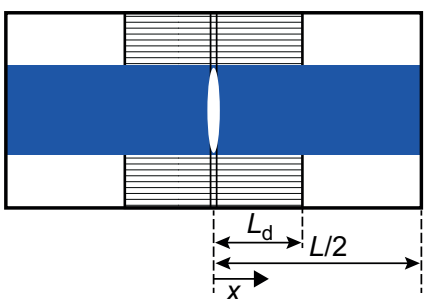

d)

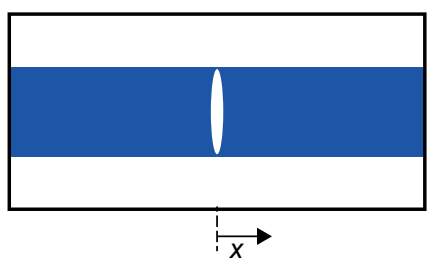

b)

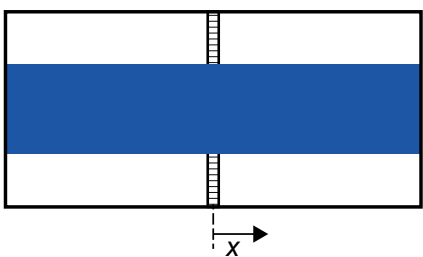

e)

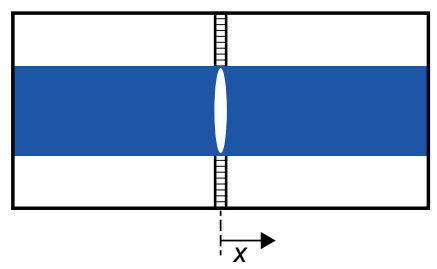

c)

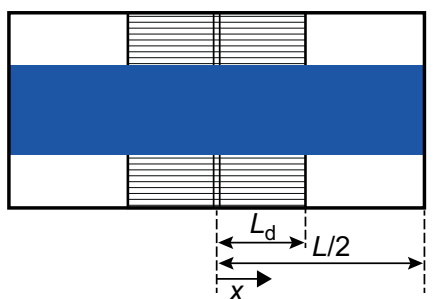

f)

Figure 7. The undamaged state and five damaged modes of the cross-ply ceramic composites: a) undamaged composite; b) mode 1: transverse cracking in the transverse ply, with debonding at the ply boundary; c) mode 2: transverse cracking and matrix cracking with perfect fibre/matrix bonding, and fracture of the fibres occurs in the longitudinal ply; d) mode 3: transverse cracking and matrix cracking with fibre/matrix debonding and sliding in the longitudinal ply; e) mode 4: matrix cracking with perfect fibre/ matrix bonding, and fracture of the fibres occurs in the longitudinal ply; and f) mode 5: matrix cracking and fibre/matrix interface debonding and sliding in the longitudinal ply. 
Figure 8. A unit cell is extracted from the CMCs, which contains a single fibre surrounded by a hollow cylinder of the matrix. The fibre radius is $r_{\mathrm{f}}$, and the matrix radius is $R\left(R=\mathrm{r}_{\mathrm{f}} / V_{\mathrm{f}}^{1 / 2}\right)$. The length of the unit cell is $L / 2$, which is half of the matrix crack spacing, and the interface de-bonded length is $L_{\mathrm{d}}$. Upon unloading, a counter slip occurs in the interface de-bonded region. The interface de-bonded region can be divided into two regions, i.e., the interface counter-slip region and the interface slip region, as shown in Figure 8a. The interface counterslip length is denoted as $y$. Upon reloading, a new slip occurs in the interface de-bonded region. The interface de-bonded region can be divided into three regions, i.e., the interface new-slip region, the interface counter-slip region, and the interface slip region, as shown in Figure $8 \mathrm{~b}$. The interface new-slip region is denoted as $\mathrm{z}$. Based

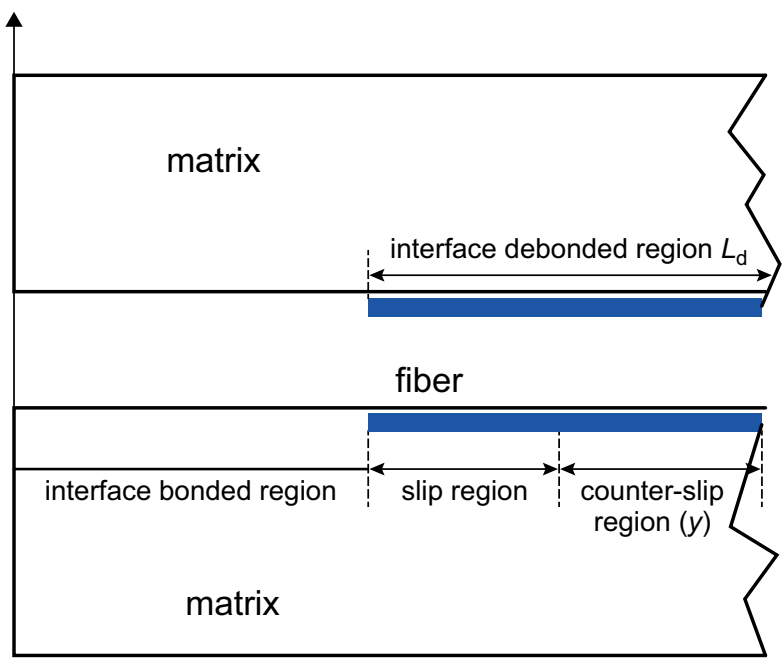

a)

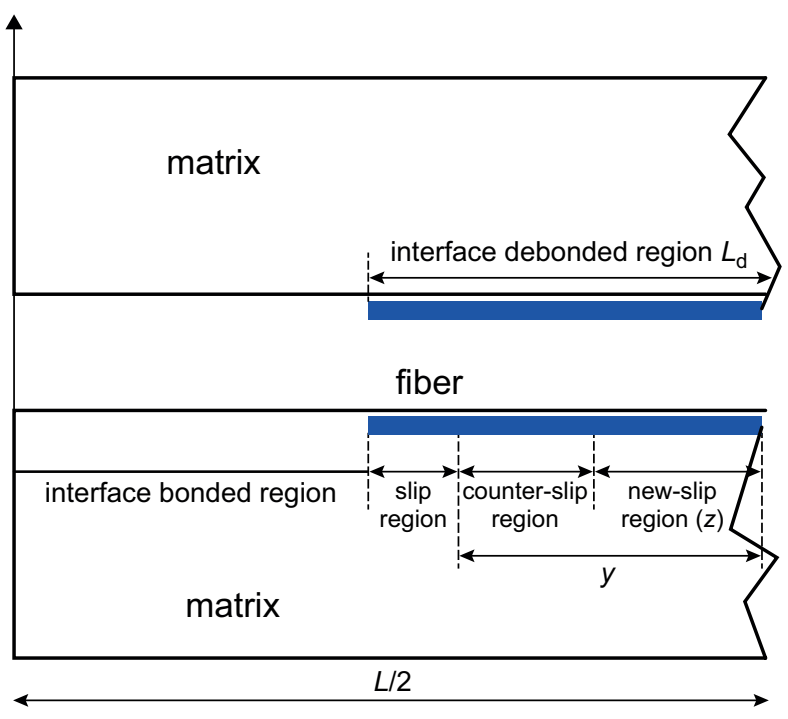

b)

Figure 8. The schematic figure for the fibre sliding relative to the matrix upon: a) unloading; and b) reloading. on the damage mechanism of the fibre sliding relative to the matrix upon unloading/reloading, the hysteresis loops can be divided into four different cases, including:

- Case I: the fibre/matrix interface partially debonding and the fibre completely sliding relative to the matrix in the interface de-bonded region;

- Case II: the fibre/matrix interface partially debonding and the fibre partially sliding relative to the matrix in the interface de-bonded region;

- Case III: the fibre/matrix interface completely debonding and the fibre partially sliding relative to the matrix in the interface de-bonded region;

- Case IV: the fibre/matrix interface completely debonding and the fibre completely sliding relative to the matrix in the interface de-bonded region.

\section{Matrix cracking mode III}

The unloading strain $\varepsilon_{\mathrm{cu}}$ and reloading strain $\varepsilon_{\mathrm{cr}}$ corresponding to the interface slip in Case I and Case II can be described using the following equations.

$$
\begin{aligned}
& \varepsilon_{\mathrm{cu}}= \frac{\sigma}{V_{\mathrm{f} \_ \text {axial }} E_{\mathrm{f}}}+4 \frac{\tau_{\mathrm{i}}}{E_{\mathrm{f}}} \frac{y^{2}}{r_{\mathrm{f}} L}- \\
&-2 \frac{\tau_{\mathrm{i}}}{E_{\mathrm{f}}} \frac{\left(2 y-L_{\mathrm{d}}\right)\left(2 y-L+L_{\mathrm{d}}\right)}{r_{\mathrm{f}} L}-\left(\alpha_{\mathrm{c}}-\alpha_{\mathrm{f}}\right) \Delta \mathrm{T} \\
& \varepsilon_{\mathrm{cr}}=\frac{\sigma}{V_{\mathrm{f} \_ \text {axial }} E_{\mathrm{f}}}-4 \frac{\tau_{\mathrm{i}}}{E_{\mathrm{f}}} \frac{z^{2}}{r_{\mathrm{f}} L}+\frac{4 \tau_{\mathrm{i}}}{E_{\mathrm{f}}} \frac{(y-2 z)^{2}}{r_{\mathrm{f}} L}+ \\
& \quad+2 \frac{\tau_{\mathrm{i}}}{E_{\mathrm{f}}} \frac{\left(L_{\mathrm{d}}+2 y-2 z-L\right)}{r_{\mathrm{f}} L}-\left(\alpha_{\mathrm{c}}-\alpha_{\mathrm{f}}\right) \Delta \mathrm{T}
\end{aligned}
$$

where $V_{\text {f axial }}$ denotes the fibre volume fraction along the loading direction; $E_{\mathrm{f}}$ denotes the fibre elastic modulus; $\tau_{\mathrm{i}}$ denotes the interface shear stress; $\alpha_{\mathrm{f}}$, and $\alpha_{\mathrm{c}}$ denote the fibre, and composite thermal expansion coefficient, respectively; and $\Delta T$ denotes the temperature difference between the fabricated temperature $T_{0}$ and testing temperature $T_{1}\left(\Delta T=T_{1}-T_{0}\right)$.

The unloading strain $\varepsilon_{\mathrm{cu}}$ and reloading strain $\varepsilon_{\mathrm{cr}}$ corresponding to the interface slip in Case III and Case IV can be described using the following equations.

$$
\begin{gathered}
\varepsilon_{\mathrm{cu}}=\frac{\sigma}{V_{\mathrm{f} \_ \text {axial }} E_{\mathrm{f}}}-4 \frac{\tau_{\mathrm{i}}}{E_{\mathrm{f}}} \frac{y^{2}}{r_{\mathrm{f}} L}- \\
-2 \frac{\tau_{\mathrm{i}}}{E_{\mathrm{f}}} \frac{(2 y-L / 2)^{2}}{r_{\mathrm{f}} L}-\left(\alpha_{\mathrm{c}}-\alpha_{\mathrm{f}}\right) \Delta \mathrm{T} \\
\varepsilon_{\mathrm{cr}}=\frac{\sigma}{V_{\mathrm{f} \_ \text {axial }} E_{\mathrm{f}}}-4 \frac{\tau_{\mathrm{i}}}{E_{\mathrm{f}}} \frac{z^{2}}{r_{\mathrm{f}} L}+4 \frac{\tau_{\mathrm{i}}}{E_{\mathrm{f}}} \frac{(y-2 z)^{2}}{r_{\mathrm{f}} L}- \\
-2 \frac{\tau_{\mathrm{i}}}{E_{\mathrm{f}}} \frac{(L / 2-2 y-2 z)^{2}}{r_{\mathrm{f}} L}-\left(\alpha_{\mathrm{c}}-\alpha_{\mathrm{f}}\right) \Delta \mathrm{T}
\end{gathered}
$$




\section{Matrix cracking mode $\mathrm{V}$}

The unloading strain $\varepsilon_{\mathrm{cu}}$ and reloading strain $\varepsilon_{\mathrm{cr}}$ corresponding to the interface slip in Case I and Case II can be described using the following equations.

$$
\begin{aligned}
& \varepsilon_{\mathrm{cu}}= \frac{1}{V_{\mathrm{f} \_ \text {axial }} E_{\mathrm{f}}}\left(\sigma-k \sigma_{\mathrm{to}}\right)+4 \frac{\tau_{\mathrm{i}}}{E_{\mathrm{f}}} \frac{y^{2}}{r_{\mathrm{f}} L}- \\
&-2 \frac{\tau_{\mathrm{i}}}{E_{\mathrm{f}}} \frac{\left(2 y-L_{\mathrm{d}}\right)\left(2 y+L_{\mathrm{d}}-L\right)}{r_{\mathrm{f}} L}-\left(\alpha_{\mathrm{c}}-\alpha_{\mathrm{f}}\right) \Delta \mathrm{T} \\
& \varepsilon_{\mathrm{cr}}= \frac{1}{V_{\mathrm{f} \_ \text {axial }} E_{\mathrm{f}}}\left(\sigma-k \sigma_{\mathrm{to}}\right)-4 \frac{\tau_{\mathrm{i}}}{E_{\mathrm{f}}} \frac{z^{2}}{r_{\mathrm{f}} L}+\frac{4 \tau_{\mathrm{i}}}{E_{\mathrm{f}}} \frac{(y-2 z)^{2}}{r_{\mathrm{f}} L}+ \\
&+2 \frac{\tau_{\mathrm{i}}}{E_{\mathrm{f}}} \frac{\left(L_{\mathrm{d}}-2 y+2 z\right)\left(L_{\mathrm{d}}+2 y-2 z-L\right)}{r_{\mathrm{f}} L}-\left(\alpha_{\mathrm{c}}-\alpha_{\mathrm{f}}\right) \Delta \mathrm{T}
\end{aligned}
$$

where $\mathrm{k}$ denotes the proportion of transverse ply in the entire composite; and $\sigma_{\text {to }}$ denotes the axial stress in the transverse ply.

The unloading strain $\varepsilon_{\mathrm{cu}}$ and reloading strain $\varepsilon_{\mathrm{cr}}$ corresponding to the interface slip in Case III and Case IV can be described using the following equations.

$$
\begin{gathered}
\varepsilon_{\mathrm{cu}}=\frac{1}{V_{\text {f_axial }} E_{\mathrm{f}}}\left(\sigma-k \sigma_{\mathrm{to}}\right)+4 \frac{\tau_{\mathrm{i}}}{E_{\mathrm{f}}} \frac{y^{2}}{r_{\mathrm{f}} L}- \\
-2 \frac{\tau_{\mathrm{i}}}{E_{\mathrm{f}}} \frac{(2 y-L / 2)^{2}}{r_{\mathrm{f}} L}-\left(\alpha_{\mathrm{c}}-\alpha_{\mathrm{f}}\right) \Delta \mathrm{T} \\
\varepsilon_{\mathrm{cr}}=\frac{1}{V_{\mathrm{f} \_a x i a l} E_{\mathrm{f}}}\left(\sigma-k \sigma_{\mathrm{to}}\right)-4 \frac{\tau_{\mathrm{i}}}{E_{\mathrm{f}}} \frac{z^{2}}{r_{\mathrm{f}} L}+4 \frac{\tau_{\mathrm{i}}}{E_{\mathrm{f}}} \frac{(y-2 z)^{2}}{r_{\mathrm{f}} L}- \\
-2 \frac{\tau_{\mathrm{i}}}{E_{\mathrm{f}}} \frac{(L / 2-2 y+2 z)^{2}}{r_{\mathrm{f}} L}-\left(\alpha_{\mathrm{c}}-\alpha_{\mathrm{f}}\right) \Delta \mathrm{T}
\end{gathered}
$$

\section{Hysteresis dissipated energy}

The fatigue hysteresis dissipated energy corresponding to the different applied cycle numbers can be described using the following equation. [15]

$$
U=\int_{\sigma_{\min }}^{\sigma_{\max }}\left[\varepsilon_{\mathrm{cu}}(\sigma)-\varepsilon_{\mathrm{cr}}(\sigma)\right] \mathrm{d} \sigma
$$

Substituting the unloading and reloading strain in Equation $2 \sim 5$ into Equation 10, the fatigue hysteresis dissipated energy of $U_{3}$ of matrix cracking mode 3 can be obtained for the different interface slips cases; substituting the unloading and reloading strain of Equation $6 \sim 9$ into Equation 10, the fatigue hysteresis dissipated energy of $U_{5}$ of matrix cracking mode 5 can also be obtained for the different interface slip cases. The composite fatigue hysteresis dissipated energy of $U_{\mathrm{c}}$ can be described using the following equation.

$$
U_{\mathrm{c}}=\eta U_{3}+(1-\eta) U_{5}
$$

where $\eta$ denotes the composite damage parameter, i.e., the proportion of matrix cracking mode 3 in the entire matrix cracking modes.

Comparing the experimental fatigue hysteresis dissipated energy with the theoretical computational values, the fibre/matrix interface shear stress of the fibre-reinforced CMCs can be obtained. The degradation rate $\psi$ of the fibre/matrix interface shear stress can be described using the following equation.

$$
\psi=\frac{\tau_{\mathrm{i}}\left(N_{\text {initial }}\right)-\tau_{\mathrm{i}}\left(N_{\text {final }}\right)}{N_{\text {initial }}-N_{\text {final }}}
$$

where $N_{\text {initial }}$ and $N_{\text {final }}$ denote the initial and final cycle number for estimating the interface shear stress; and $\tau_{\mathrm{i}}\left(N_{\text {initial }}\right)$ and $\tau_{\mathrm{i}}\left(N_{\text {final }}\right)$ denote the estimated interface shear stress at the initial and final cycle number.

\section{EXPERIMENTAL COMPARISONS}

\section{$\mathrm{SiC} / \mathrm{MAS}$ at $566^{\circ} \mathrm{C}$ in air}

At the loading frequency of $\mathrm{f}=1 \mathrm{~Hz}$, when the fatigue peak stress is $\sigma_{\max }=137 \mathrm{MPa}$, the experimental and theoretical fatigue hysteresis dissipated energy versus the the fibre/matrix interface shear stress curves are shown in Figure 9a. The theoretical fatigue hysteresis dissipated energy increases with the decreasing fibre/ matrix interface shear stress from $10.4 \mathrm{~kJ} \cdot \mathrm{m}^{-3}$ at $\tau_{\mathrm{i}}=$ $20 \mathrm{MPa}$ to the peak values of $20.8 \mathrm{~kJ} \cdot \mathrm{m}^{-3}$ at $\tau_{\mathrm{i}}=8.2 \mathrm{MPa}$, and then decreases to $0 \mathrm{~kJ} \cdot \mathrm{m}^{-3}$ at $\tau_{\mathrm{i}}=0 \mathrm{MPa}$. The experimental hysteresis dissipated energy decreases from $5.4 \mathrm{~kJ} \cdot \mathrm{m}^{-3}$ at the $4^{\text {th }}$ applied cycle to $4.4 \mathrm{~kJ} \cdot \mathrm{m}^{-3}$ at the $230^{\text {th }}$ applied cycle, which lies in the left part of the fatigue hysteresis dissipated energy versus the fibre/ matrix interface shear stress curve. Comparing the experimental fatigue hysteresis dissipated energy with the theoretical computational values, the fibre/matrix interface shear stress corresponding to the different applied cycle numbers can be obtained, as shown in Figure $9 b$, in which the fibre/matrix interface shear stress decreases from 1.2 $\mathrm{MPa}$ at the $4^{\text {th }}$ applied cycle to $1 \mathrm{MPa}$ at the $230^{\text {th }}$ applied cycle.

When the fatigue peak stress is $\sigma_{\max }=120 \mathrm{MPa}$, the experimental and theoretical fatigue hysteresis dissipated energy versus the fibre/matrix interface shear stress curves are shown in Figure 10a. The theoretical fatigue hysteresis dissipated energy increases with the decreasing fibre/matrix interface shear stress from $6.7 \mathrm{~kJ} \cdot \mathrm{m}^{-3}$ at $\tau_{\mathrm{i}}=20 \mathrm{MPa}$ to the peak values of $15.5 \mathrm{~kJ} \cdot \mathrm{m}^{-3}$ at $\tau_{\mathrm{i}}=7.2 \mathrm{MPa}$, and then decreases to $0 \mathrm{~kJ} \cdot \mathrm{m}^{-3}$ at $\tau_{\mathrm{i}}=0 \mathrm{MPa}$. The experimental fatigue hysteresis dissipated energy decreases from $4.5 \mathrm{~kJ} \cdot \mathrm{m}^{-3}$ at the $3^{\text {rd }}$ applied cycle to $3.2 \mathrm{~kJ} \cdot \mathrm{m}^{-3}$ at the $105^{\text {th }}$ applied cycle, which lies in the left part of the fatigue hysteresis dissipated energy versus the fibre/matrix interface shear stress curve. Comparing the experimental fatigue hysteresis dissipated energy with the theoretical computational values, 


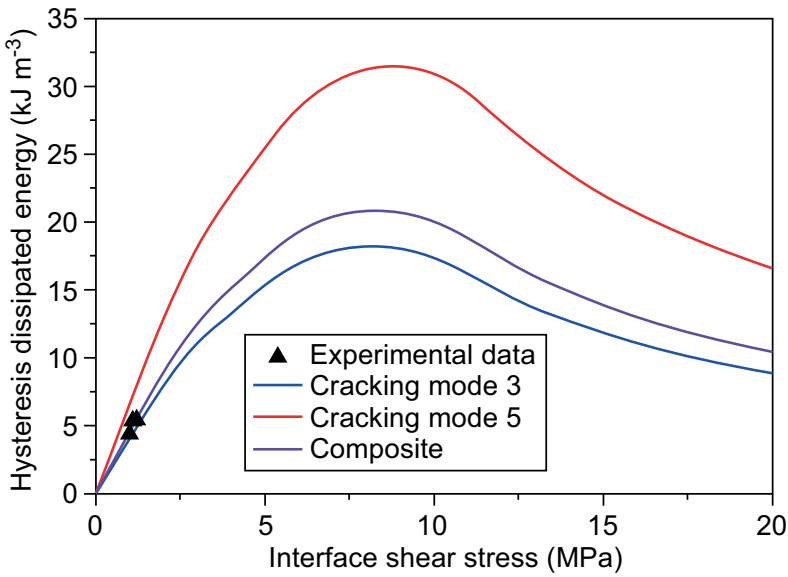

a)

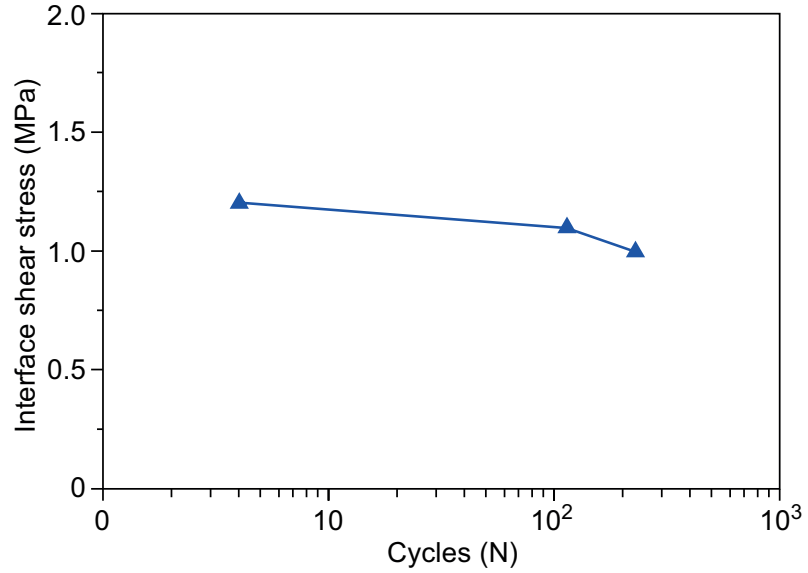

b)

Figure 9. The experimental and theoretical hysteresis dissipated energy versus the interface shear stress curves (a) and the interface shear stress versus the cycle number curve of the cross-ply SiC/MAS composite under $\sigma_{\max }=137 \mathrm{MPa}$ and the loading frequency of $1 \mathrm{~Hz}$ at $566{ }^{\circ} \mathrm{C}$ in air (b).

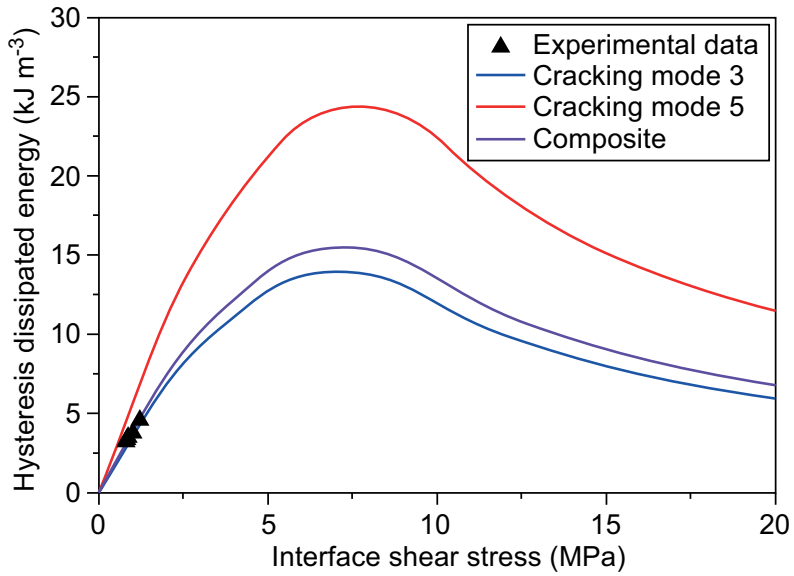

a)

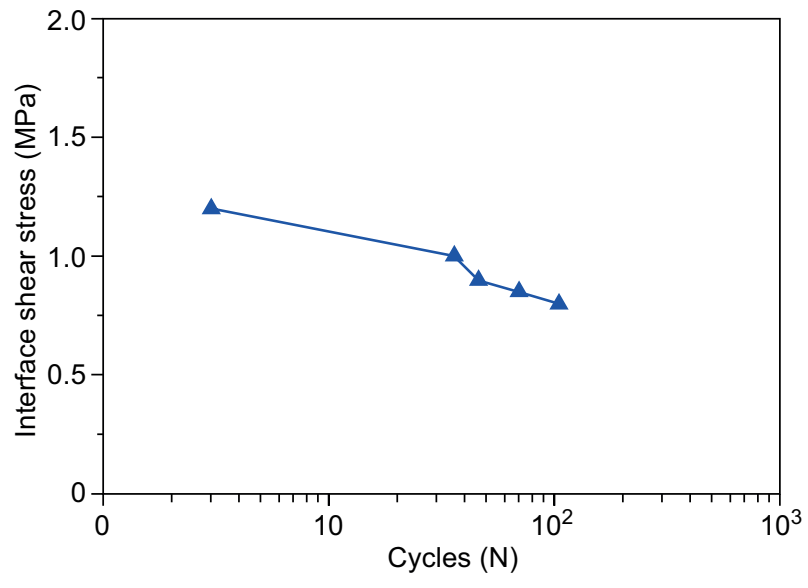

b)

Figure 10. The experimental and theoretical hysteresis dissipated energy versus the interface shear stress curves (a) and the interface shear stress versus the cycle number curve of the cross-ply SiC/MAS composite under $\sigma_{\max }=120 \mathrm{MPa}$ and the loading frequency of $1 \mathrm{~Hz}$ at $566^{\circ} \mathrm{C}$ in air (b).

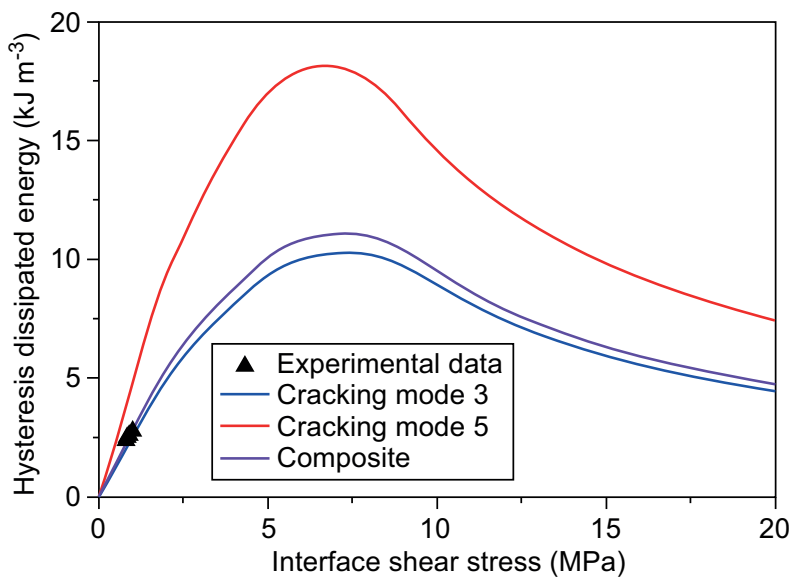

a)

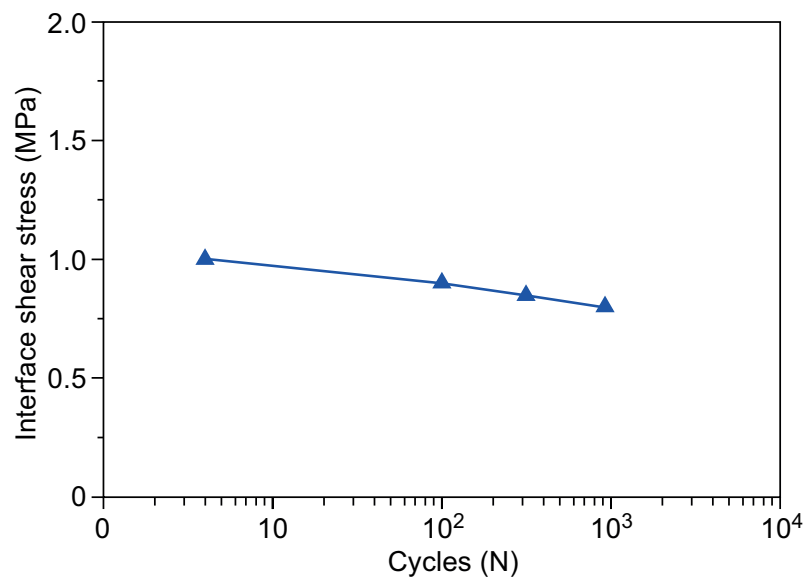

b)

Figure 11. The experimental and theoretical hysteresis dissipated energy versus the interface shear stress curves (a) and the interface shear stress versus the cycle number curve of the cross-ply SiC/MAS composite under $\sigma_{\max }=103 \mathrm{MPa}$ and the loading frequency of $1 \mathrm{~Hz}$ at $566^{\circ} \mathrm{C}$ in air (b). 


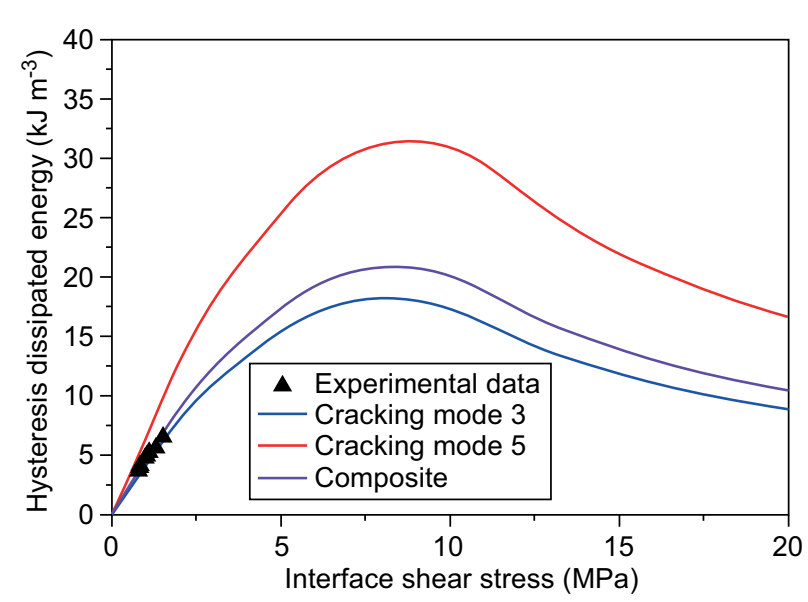

a)

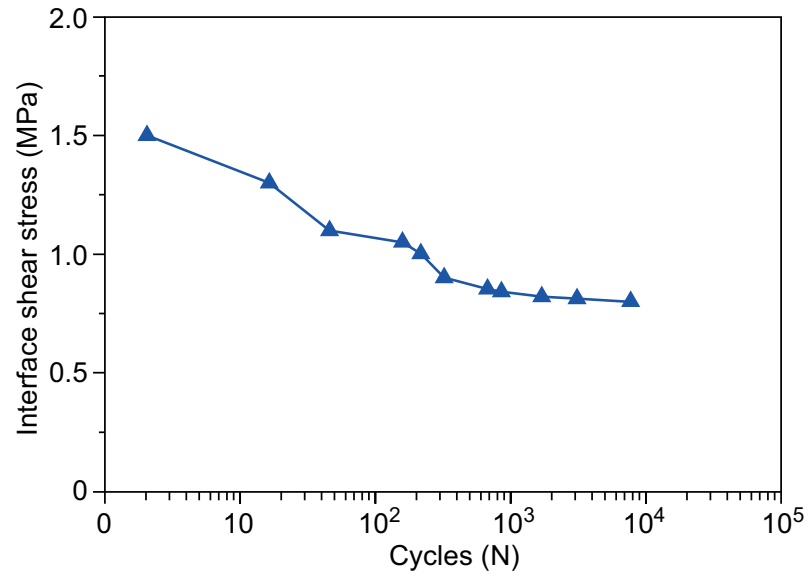

b)

Figure 12. The experimental and theoretical hysteresis dissipated energy versus the interface shear stress curves (a) and the interface shear stress versus the cycle number curve of the cross-ply SiC/MAS composite under $\sigma_{\max }=137 \mathrm{MPa}$ and the loading frequency of $10 \mathrm{~Hz}$ at $566^{\circ} \mathrm{C}$ in air (b).

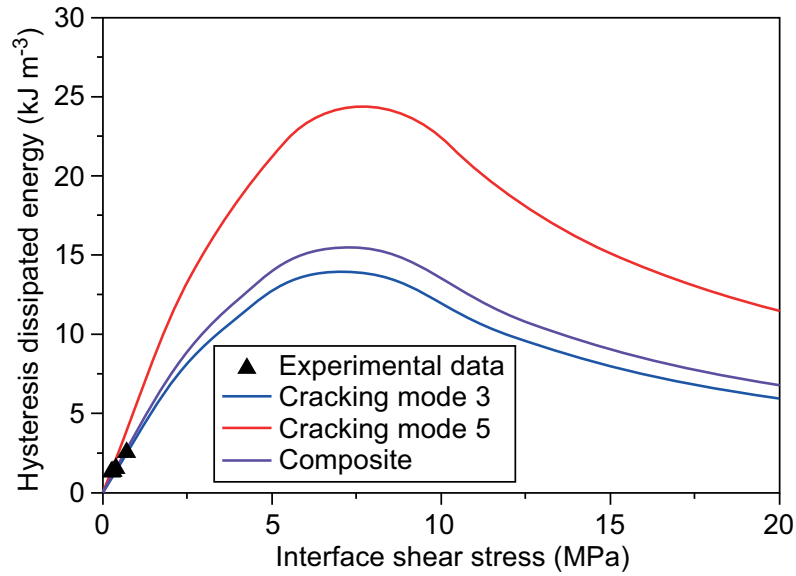

a)

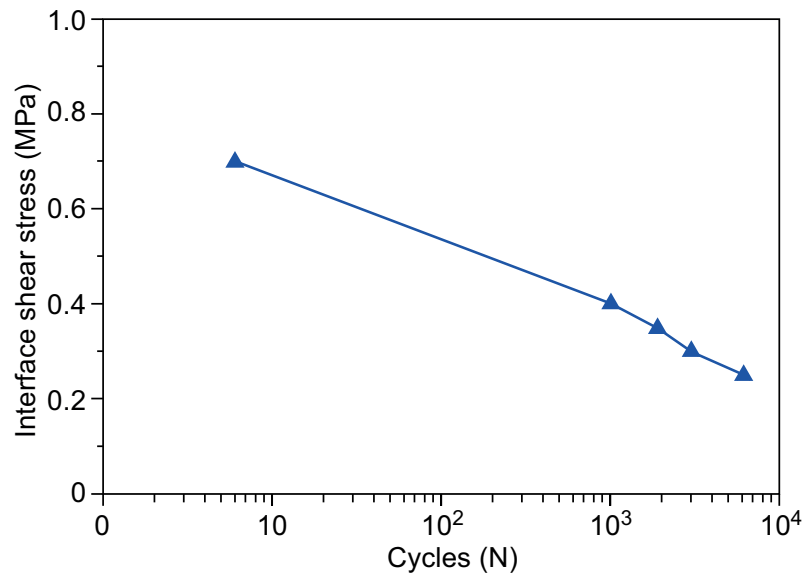

b)

Figure 13. The experimental and theoretical hysteresis dissipated energy versus the interface shear stress curves (a) and the interface shear stress versus the cycle number curve of the cross-ply SiC/MAS composite under $\sigma_{\max }=120 \mathrm{MPa}$ and the loading frequency of $10 \mathrm{~Hz}$ at $566^{\circ} \mathrm{C}$ in air (b).

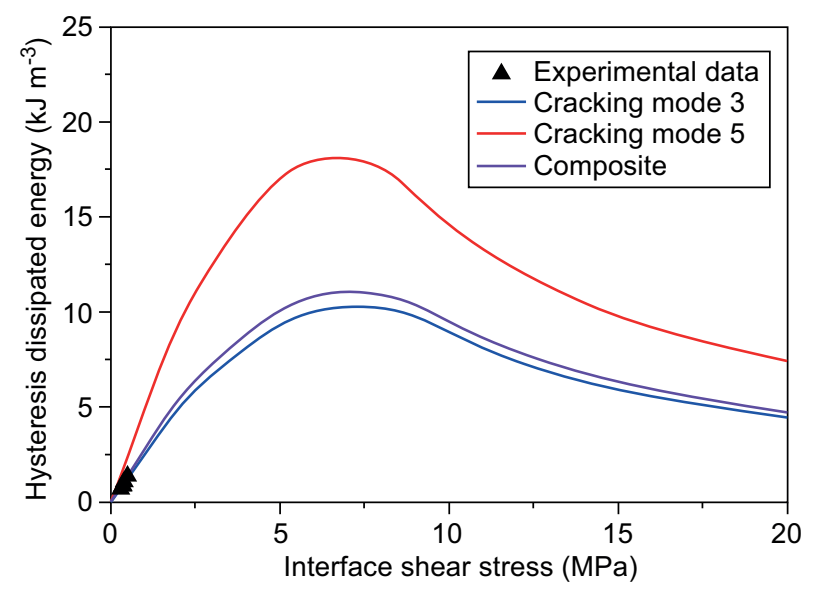

a)

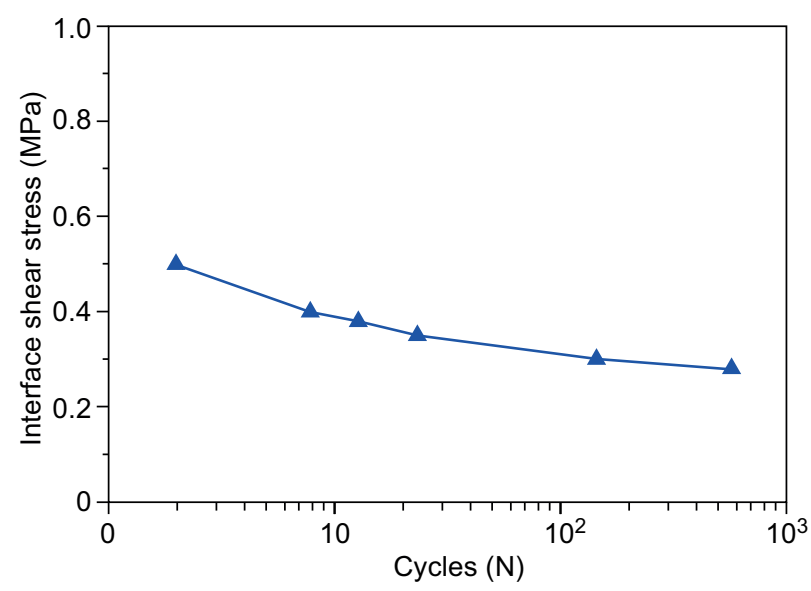

b)

Figure 14. The experimental and theoretical hysteresis dissipated energy versus the interface shear stress curves (a) and the interface shear stress versus the cycle number curve of the cross-ply SiC/MAS composite under $\sigma_{\max }=103 \mathrm{MPa}$ and the loading frequency of $10 \mathrm{~Hz}$ at $566^{\circ} \mathrm{C}$ in air (b). 
the fibre/matrix interface shear stress corresponding to the different applied cycle numbers can be obtained, as shown in Figure 10b, in which the fibre/matrix interface shear stress decreases from 1.2 $\mathrm{MPa}$ at the 3rd applied cycle to $0.8 \mathrm{MPa}$ at the $105^{\text {th }}$ applied cycle.

When the fatigue peak stress is $\sigma_{\max }=103 \mathrm{MPa}$, the experimental and theoretical fatigue hysteresis dissipated energy versus the fibre/matrix interface shear stress curves are shown in Figure 11a. The theoretical fatigue hysteresis dissipated energy increases with the decreasing fiber/matrix interface shear stress from $4.7 \mathrm{~kJ} \cdot \mathrm{m}^{-3}$ at $\tau_{\mathrm{i}}=20 \mathrm{MPa}$ to the peak values of $11 \mathrm{~kJ} \cdot \mathrm{m}^{-3}$ at $\tau_{\mathrm{i}}=7 \mathrm{MPa}$, and then decreases to $0 \mathrm{~kJ} \cdot \mathrm{m}^{-3}$ at $\tau_{\mathrm{i}}=0 \mathrm{MPa}$. The experimental fatigue hysteresis dissipated energy decreases from $2.7 \mathrm{~kJ} \cdot \mathrm{m}^{-3}$ at the $4^{\text {th }}$ applied cycle to $2.4 \mathrm{~kJ} \cdot \mathrm{m}^{-3}$ at the $920^{\text {th }}$ applied cycle, which lies in the left part of the fatigue hysteresis dissipated energy versus the fibre/matrix interface shear stress curve. Comparing the experimental fatigue hysteresis dissipated energy with the theoretical computational values, the fibre/matrix interface shear stress corresponding to the different applied cycle numbers can be obtained, as shown in Figure 11b, in which the fibre/matrix interface shear stress decreases from $1 \mathrm{MPa}$ at the $4^{\text {th }}$ applied cycle to $0.8 \mathrm{MPa}$ at the $920^{\text {th }}$ applied cycle.

At the loading frequency of $f=10 \mathrm{~Hz}$, when the fatigue peak stress is $\sigma_{\max }=137 \mathrm{MPa}$, the experimental fatigue hysteresis dissipated energy decreases from $6.5 \mathrm{~kJ} \cdot \mathrm{m}^{-3}$ at the $2^{\text {nd }}$ applied cycle to $3.6 \mathrm{~kJ} \cdot \mathrm{m}^{-3}$ at the $7730^{\text {th }}$ applied cycle, which lies in the left part of the theoretical fatigue hysteresis dissipated energy versus the fibre/matrix interface shear stress curve, as shown in Figure 12a. Comparing the experimental fatigue hysteresis dissipated energy with the theoretical computational values, the fibre/matrix interface shear stress corresponding to the different applied cycle numbers can be obtained, as shown in Figure 12b, in which the fibre/

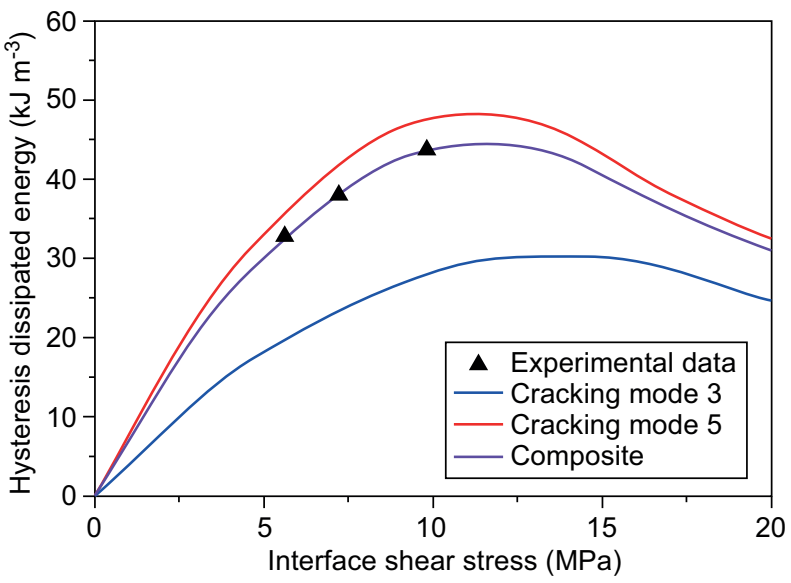

a) matrix interface shear stress decreases from 1.5 MPa at the $2^{\text {nd }}$ applied cycle to $0.8 \mathrm{MPa}$ at the $7730^{\text {th }}$ applied cycle.

When the fatigue peak stress is $\sigma_{\max }=120 \mathrm{MPa}$, the experimental fatigue hysteresis dissipated energy decreases from $2.5 \mathrm{~kJ} \cdot \mathrm{m}^{-3}$ at the $6^{\text {th }}$ applied cycle to $1.3 \mathrm{~kJ} \cdot \mathrm{m}^{-3}$ at the $6150^{\text {th }}$ applied cycle, which lies in the left part of the theoretical fatigue hysteresis dissipated energy versus the fibre/matrix interface shear stress curve, as shown in Figure 13a. Comparing the experimental fatigue hysteresis dissipated energy with the theoretical computational values, the fibre/matrix interface shear stress corresponding to the different applied cycle numbers can be obtained, as shown in Figure 13b, in which the fibre/matrix interface shear stress decreases from $0.7 \mathrm{MPa}$ at the $6^{\text {th }}$ applied cycle to $0.25 \mathrm{MPa}$ at the $6150^{\text {th }}$ applied cycle.

When the fatigue peak stress is $\sigma_{\max }=103 \mathrm{MPa}$, the experimental fatigue hysteresis dissipated energy decreases from $1.3 \mathrm{~kJ} \cdot \mathrm{m}^{-3}$ at the $2^{\text {nd }}$ applied cycle to $0.7 \mathrm{~kJ} \cdot \mathrm{m}^{-3}$ at the $572^{\text {th }}$ applied cycle, which lies in the left part of the theoretical fatigue hysteresis dissipated energy versus the fibre/matrix interface shear stress curve, as shown in Figure 14a. Comparing the experimental fatigue hysteresis dissipated energy with the theoretical computational values, the fibre/matrix interface shear stress corresponding to the different applied cycle numbers can be obtained, as shown in Figure $14 \mathrm{~b}$, in which the interface shear stress decreases from $0.5 \mathrm{MPa}$ at the $2^{\text {nd }}$ applied cycle to $0.28 \mathrm{MPa}$ at the $572^{\text {th }}$ applied cycle.

\section{$\mathrm{SiC} / \mathrm{MAS}$ at $1093{ }^{\circ} \mathrm{C}$ in air}

At the loading frequency of $f=1 \mathrm{~Hz}$, when the fatigue peak stress is $\sigma_{\max }=137 \mathrm{MPa}$, the experimental and theoretical fatigue hysteresis dissipated energy

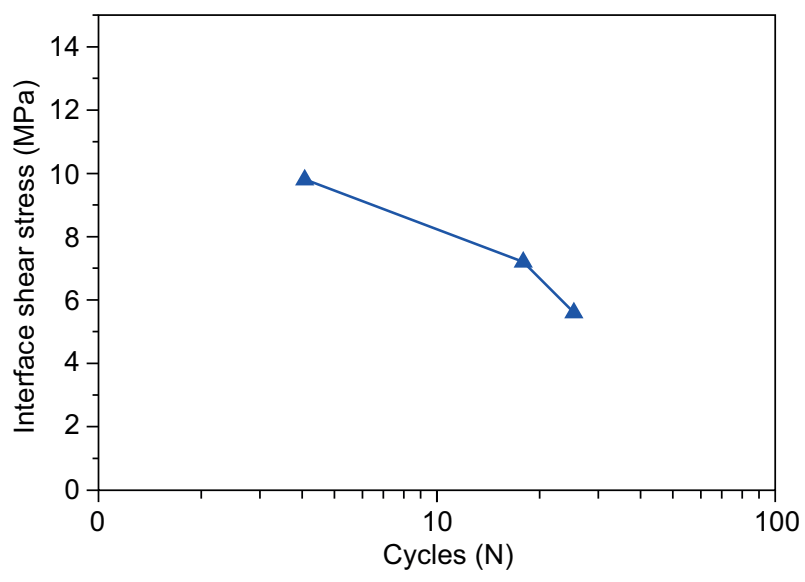

b)

Figure 15. The experimental and theoretical hysteresis dissipated energy versus the interface shear stress curves (a) and the interface shear stress versus the cycle number curve of the cross-ply SiC/MAS composite under $\sigma_{\max }=137 \mathrm{MPa}$ and the loading frequency of $1 \mathrm{~Hz}$ at $1093{ }^{\circ} \mathrm{C}$ in air (b). 


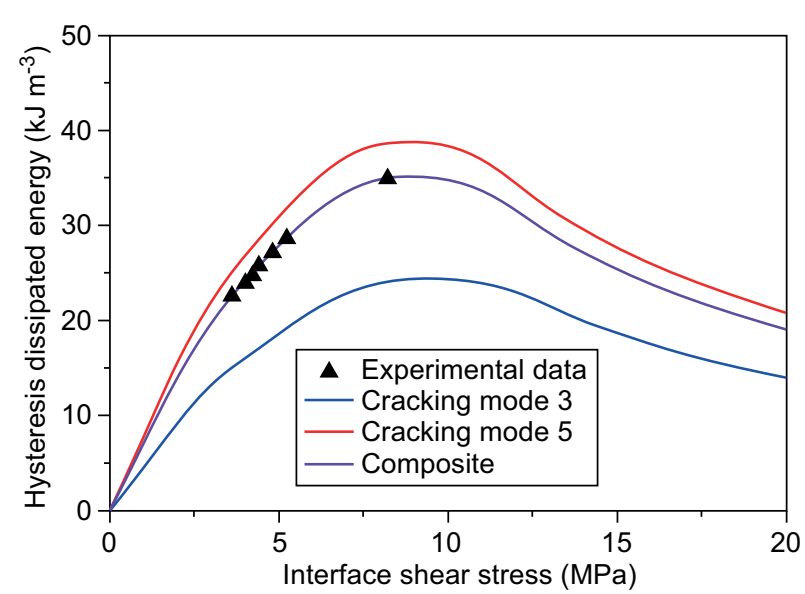

a)

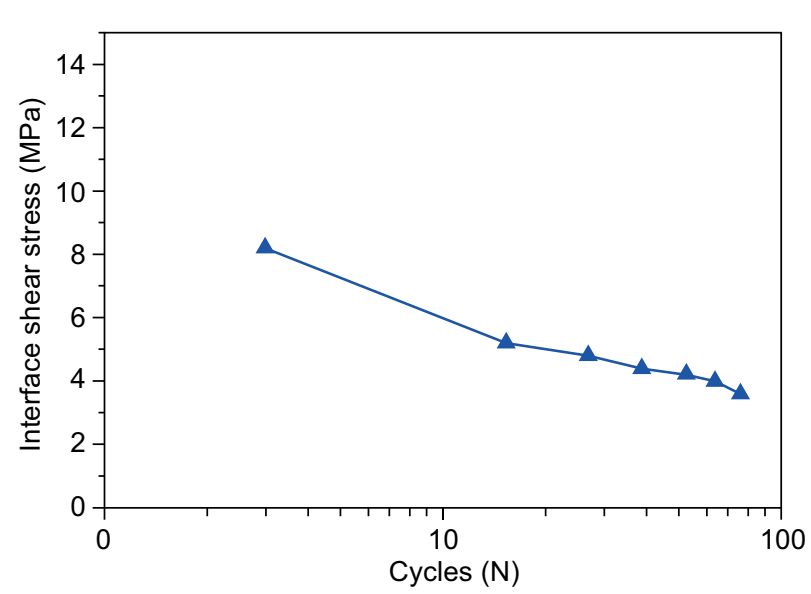

b)

Figure 16. The experimental and theoretical hysteresis dissipated energy versus the interface shear stress curves (a) and the interface shear stress versus the cycle number curve of the cross-ply SiC/MAS composite under $\sigma_{\max }=120 \mathrm{MPa}$ and the loading frequency of $1 \mathrm{~Hz}$ at $1093^{\circ} \mathrm{C}$ in air (b).

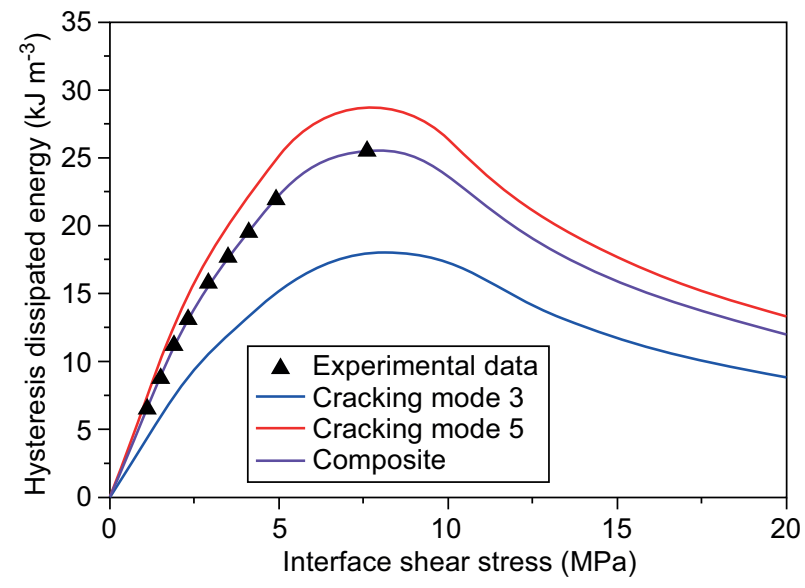

a)

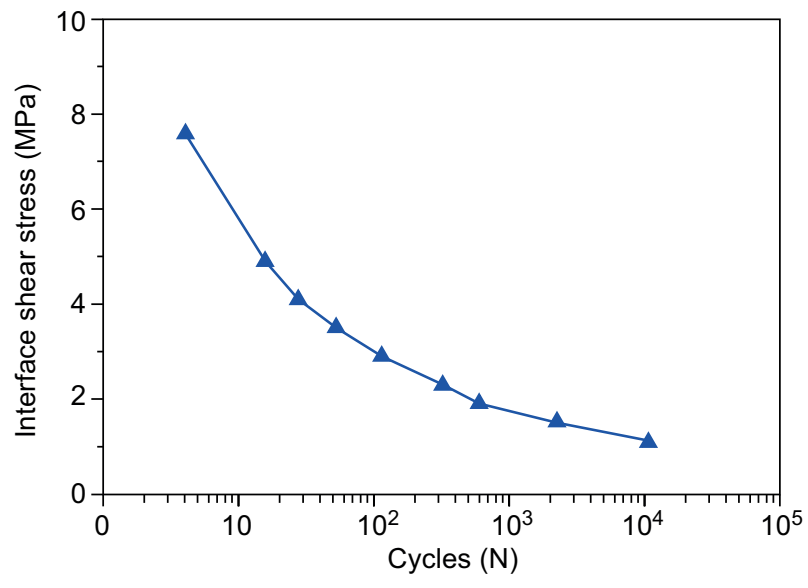

b)

Figure 17. The experimental and theoretical hysteresis dissipated energy versus the interface shear stress curves (a) and the interface shear stress versus the cycle number curve of the cross-ply SiC/MAS composite under $\sigma_{\max }=103 \mathrm{MPa}$ and the loading frequency of $1 \mathrm{~Hz}$ at $1093{ }^{\circ} \mathrm{C}$ in air (b).

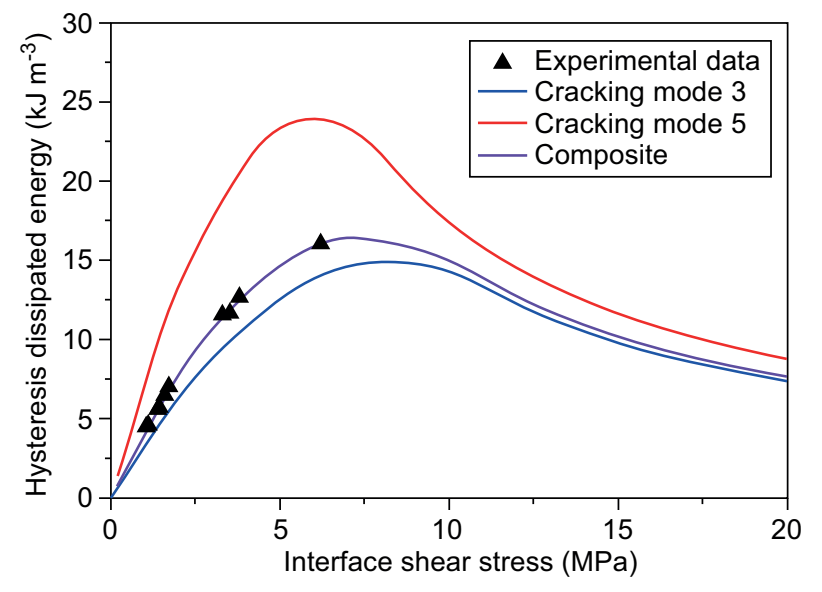

a)

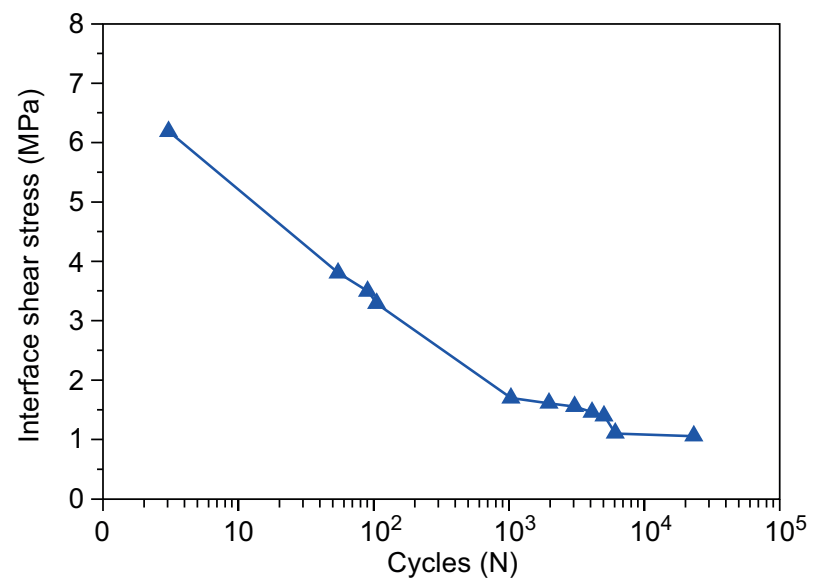

b)

Figure 18. The experimental and theoretical hysteresis dissipated energy versus the interface shear stress curves (a) and the interface shear stress versus the cycle number curve of the cross-ply SiC/MAS composite under $\sigma_{\max }=96 \mathrm{MPa}$ and the loading frequency of $1 \mathrm{~Hz}$ at $1093{ }^{\circ} \mathrm{C}$ in air (b). 
versus the fibre/matrix interface shear stress curves are shown in Figure 15a. The theoretical fatigue hysteresis dissipated energy increases with the decreasing fibre/ matrix interface shear stress from $31 \mathrm{~kJ} \cdot \mathrm{m}^{-3}$ at $\tau_{\mathrm{i}}=20$ to the peak values of $44.5 \mathrm{~kJ} \cdot \mathrm{m}^{-3}$ at $\tau_{\mathrm{i}}=11.4 \mathrm{MPa}$, and then decreases to $0 \mathrm{~kJ} \cdot \mathrm{m}^{-3}$ at $\tau_{\mathrm{i}}=0 \mathrm{MPa}$. The experimental fatigue hysteresis dissipated energy decreases from $43.8 \mathrm{~kJ} \cdot \mathrm{m}^{-3}$ at the $4^{\text {th }}$ applied cycle to $32.8 \mathrm{~kJ} \cdot \mathrm{m}^{-3}$ at the $25^{\text {th }}$ applied cycle, which lies in the left part of the fatigue hysteresis dissipated energy versus the fibre/ matrix interface shear stress curve. Comparing the experimental fatigue hysteresis dissipated energy with the theoretical computational values, the fibre/matrix interface shear stress corresponding to the different cycle numbers can be obtained, as shown in Figure $15 \mathrm{~b}$, in which the interface shear stress decreases from $9.8 \mathrm{MPa}$ at the $4^{\text {th }}$ applied cycle to $5.6 \mathrm{MPa}$ at the $25^{\text {th }}$ applied cycle.

When the fatigue peak stress is $\sigma_{\max }=120 \mathrm{MPa}$, the experimental and theoretical hysteresis dissipated energy versus the fibre/matrix interface shear stress curves are shown in Figure 16a. The theoretical fatigue hysteresis dissipated energy increases with the decreasing interface shear stress from $19 \mathrm{~kJ} \cdot \mathrm{m}^{-3}$ at $\tau_{\mathrm{i}}=20 \mathrm{MPa}$ to the peak values of $35.1 \mathrm{~kJ} \cdot \mathrm{m}^{-3}$ at $\tau_{\mathrm{i}}=9 \mathrm{MPa}$, and then decreases to $0 \mathrm{~kJ} \cdot \mathrm{m}^{-3}$ at $\tau_{\mathrm{i}}=0 \mathrm{MPa}$. The experimental fatigue hysteresis dissipated energy decreases from $34.9 \mathrm{~kJ} \cdot \mathrm{m}^{-3}$ at the $3^{\text {rd }}$ applied cycle to $22.5 \mathrm{~kJ} \cdot \mathrm{m}^{-3}$ at the $76^{\text {th }}$ applied cycle, which lies in the left part of the fatigue hysteresis dissipated energy versus the fibre/matrix interface shear stress curve. By comparing the experimental fatigue hysteresis dissipated energy with the theoretical computational values, the fibre/matrix interface shear stress corresponding to the different applied cycle numbers can be obtained, as shown in Figure 16b, in which the fibre/ matrix interface shear stress decreases from 8.2 MPa at the $3 \mathrm{rd}$ applied cycle to $3.6 \mathrm{MPa}$ at the $76^{\text {th }}$ applied cycle.

When the fatigue peak stress is $\sigma_{\max }=103 \mathrm{MPa}$, the experimental and theoretical fatigue hysteresis dissipated energy versus the fibre/matrix interface shear stress curves are shown in Figure 17a. The theoretical fatigue hysteresis dissipated energy increases with the decreasing fibre/matrix interface shear stress from $11.9 \mathrm{~kJ} \cdot \mathrm{m}^{-3}$ at $\tau_{\mathrm{i}}=20 \mathrm{MPa}$ to the peak values of $25.5 \mathrm{~kJ} \cdot \mathrm{m}^{-}$ ${ }^{3}$ at $\tau_{\mathrm{i}}=7.8 \mathrm{MPa}$, and then decreases to $0 \mathrm{~kJ} \mathrm{~m}^{-3}$ at $\tau_{\mathrm{i}}=$ $0 \mathrm{MPa}$. The experimental fatigue hysteresis dissipated energy decreases from $25.5 \mathrm{~kJ} \cdot \mathrm{m}^{-3}$ at the $4^{\text {th }}$ applied cycle to $6.5 \mathrm{~kJ} \cdot \mathrm{m}^{-3}$ at the $10608^{\text {th }}$ applied cycle, which lies in the left part of the fatigue hysteresis dissipated energy versus the fibre/matrix interface shear stress curve. Comparing the experimental fatigue hysteresis dissipated energy with the theoretical computational values, the fibre/ matrix interface shear stress corresponding to the different applied cycle numbers can be obtained, as shown in Figure 17b, in which the fibre/matrix interface shear stress decreases from $7.6 \mathrm{MPa}$ at the $4^{\text {th }}$ applied cycle to $1.1 \mathrm{MPa}$ at the $10608^{\text {th }}$ applied cycle.
When the fatigue peak stress is $\sigma_{\max }=96 \mathrm{MPa}$, the experimental and theoretical hysteresis dissipated energy versus the fibre/matrix interface shear stress curves are shown in Figure 18a. The theoretical fatigue hysteresis dissipated energy increases with the decreasing fibre/matrix interface shear stress from $7.6 \mathrm{~kJ} \cdot \mathrm{m}^{-3}$ at $\tau_{\mathrm{i}}=20 \mathrm{MPa}$ to the peak values of $16.4 \mathrm{~kJ} \cdot \mathrm{m}^{-3}$ at $\tau_{\mathrm{i}}=$ $7.2 \mathrm{MPa}$, and then decreases to $0 \mathrm{~kJ} \cdot \mathrm{m}^{-3}$ at $\tau_{\mathrm{i}}=0 \mathrm{MPa}$. The experimental fatigue hysteresis dissipated energy decreases from $16 \mathrm{~kJ} \cdot \mathrm{m}^{-3}$ at the $3^{\text {rd }}$ applied cycle to $4.2 \mathrm{~kJ} \cdot \mathrm{m}^{-3}$ at the $33300^{\text {th }}$ applied cycle, which lies in the left part of the fatigue hysteresis dissipated energy versus the fibre/matrix interface shear stress curve. Comparing the experimental fatigue hysteresis dissipated energy with the theoretical computational values, the fibre/ matrix interface shear stress corresponding to the different applied cycle numbers can be obtained, as shown in Figure 18b, in which the fibre/matrix interface shear stress decreases from 6.2 $\mathrm{MPa}$ at the $3^{\text {rd }}$ applied cycle to $1 \mathrm{MPa}$ at the $33300^{\text {th }}$ applied cycle.

At the loading frequency of $f=10 \mathrm{~Hz}$, when the fatigue peak stress is $\sigma_{\max }=103 \mathrm{MPa}$, the experimental fatigue hysteresis dissipated energy decreases from $13 \mathrm{~kJ} \cdot \mathrm{m}^{-3}$ at the $6^{\text {th }}$ applied cycle to $3.1 \mathrm{~kJ} \cdot \mathrm{m}^{-3}$ at the $94044^{\text {th }}$ applied cycle, which lies in the left part of the theoretical fatigue hysteresis dissipated energy versus the fibre/matrix interface shear stress curve, as shown in Figure 19a. Comparing the experimental fatigue hysteresis dissipated energy with the theoretical computational values, the fibre/matrix interface shear stress corresponding to the different applied cycle numbers can be obtained, as shown in Figure 19b, in which the fibre/matrix interface shear stress decreases from 2.4 MPa at the $6^{\text {th }}$ applied cycle to $0.6 \mathrm{MPa}$ at the $94044^{\text {th }}$ applied cycle.

When the fatigue peak stress is $\sigma_{\max }=96 \mathrm{MPa}$, the experimental fatigue hysteresis dissipated energy decreases from $8.1 \mathrm{~kJ} \cdot \mathrm{m}^{-3}$ at the $6^{\text {th }}$ applied cycle to $3.6 \mathrm{~kJ} \cdot \mathrm{m}^{-3}$ at the $28400^{\text {th }}$ applied cycle, which lies in the left part of the theoretical fatigue hysteresis dissipated energy versus the fibre/matrix interface shear stress curve, as shown in Figure 20a. Comparing the experimental fatigue hysteresis dissipated energy with the theoretical computational values, the fibre/matrix interface shear stress corresponding to the different cycle numbers can be obtained, as shown in Figure 20b, in which the fibre/ matrix interface shear stress decreases from 2.1 $\mathrm{MPa}$ at the $6^{\text {th }}$ applied cycle to $0.85 \mathrm{MPa}$ at the $28400^{\text {th }}$ applied cycle.

When the fatigue peak stress is $\sigma_{\max }=86 \mathrm{MPa}$, the experimental fatigue hysteresis dissipated energy decreases from $7.2 \mathrm{~kJ} \cdot \mathrm{m}^{-3}$ at the $6^{\text {th }}$ applied cycle to $1.6 \mathrm{~kJ} \cdot \mathrm{m}^{-3}$ at the $1063330^{\text {th }}$ applied cycle, which lies in the left part of the theoretical fatigue hysteresis dissipated energy versus the fibre/matrix interface shear stress curve, as shown in Figure 21a. Comparing the experimental fatigue hysteresis dissipated energy with 


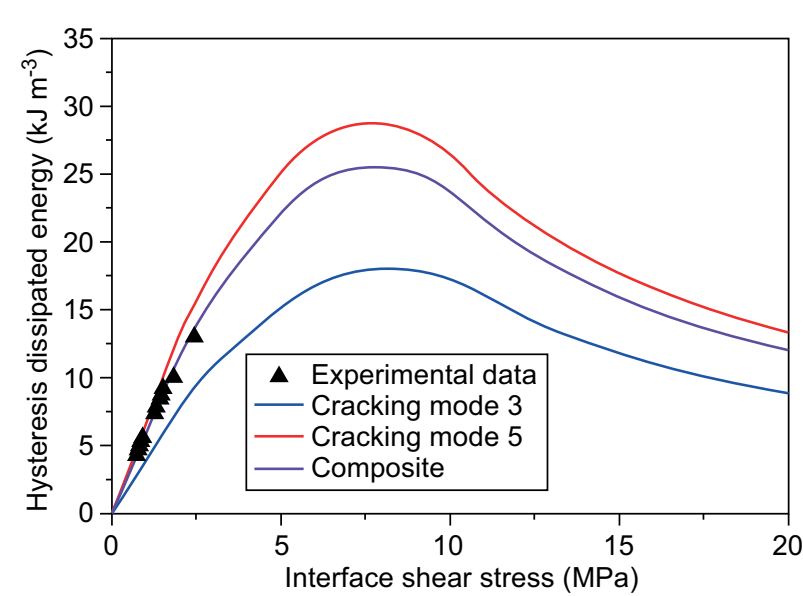

a)

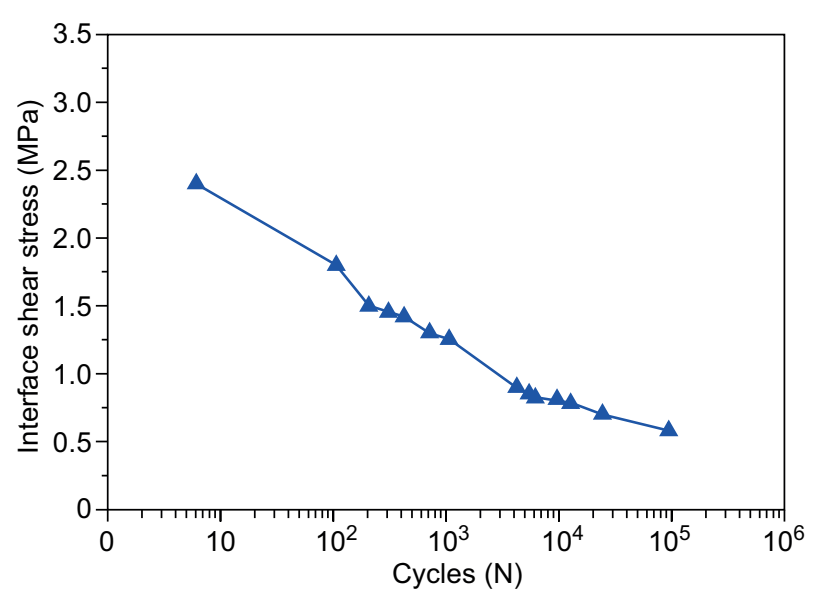

b)

Figure 19. The experimental and theoretical hysteresis dissipated energy versus the interface shear stress curves (a) and the interface shear stress versus the cycle number curve of the cross-ply SiC/MAS composite under $\sigma_{\max }=103 \mathrm{MPa}$ and the loading frequency of $10 \mathrm{~Hz}$ at $1093{ }^{\circ} \mathrm{C}$ in air (b).

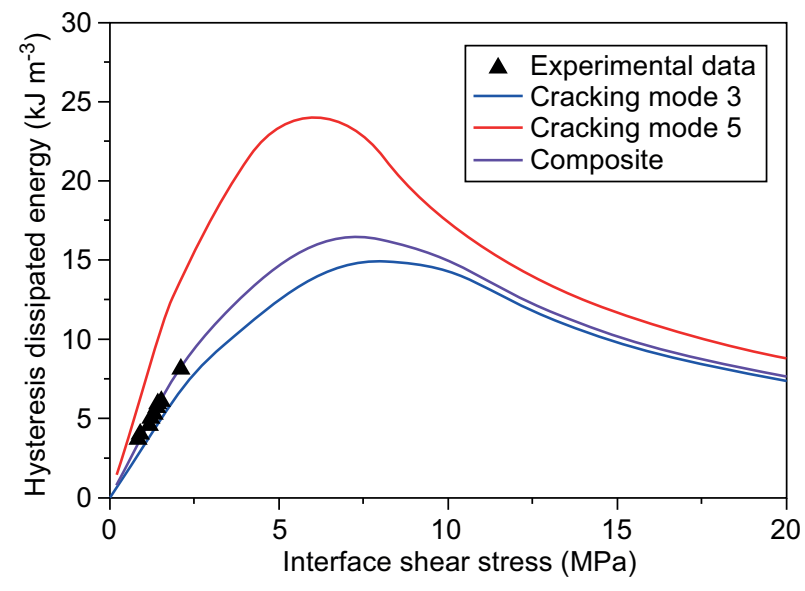

a)

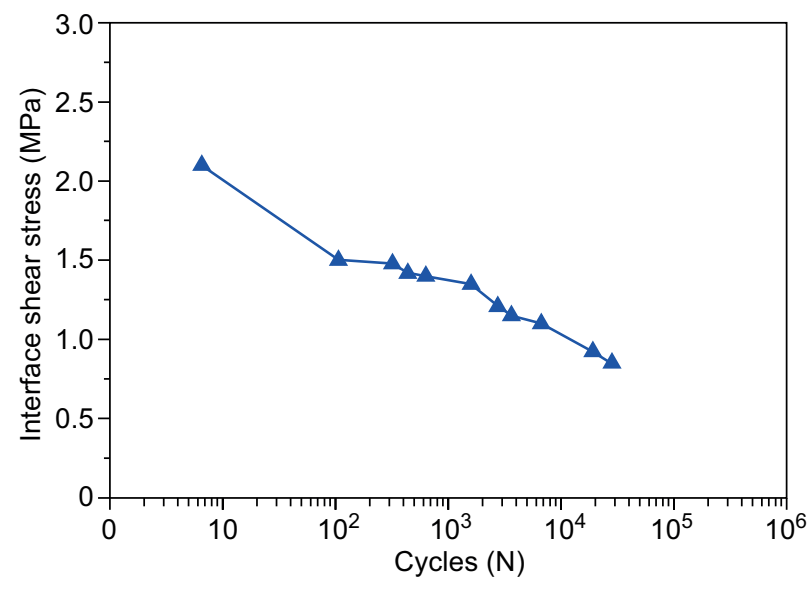

b)

Figure 20. The experimental and theoretical hysteresis dissipated energy versus the interface shear stress curves (a) and the interface shear stress versus the cycle number curve of the cross-ply SiC/MAS composite under $\sigma_{\max }=96 \mathrm{MPa}$ and the loading frequency of $10 \mathrm{~Hz}$ at $1093{ }^{\circ} \mathrm{C}$ in air (b).

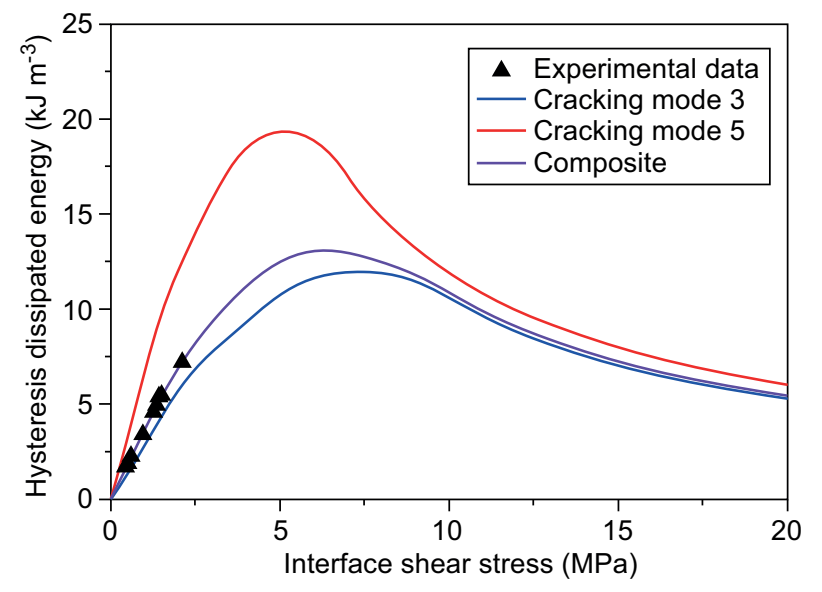

a)

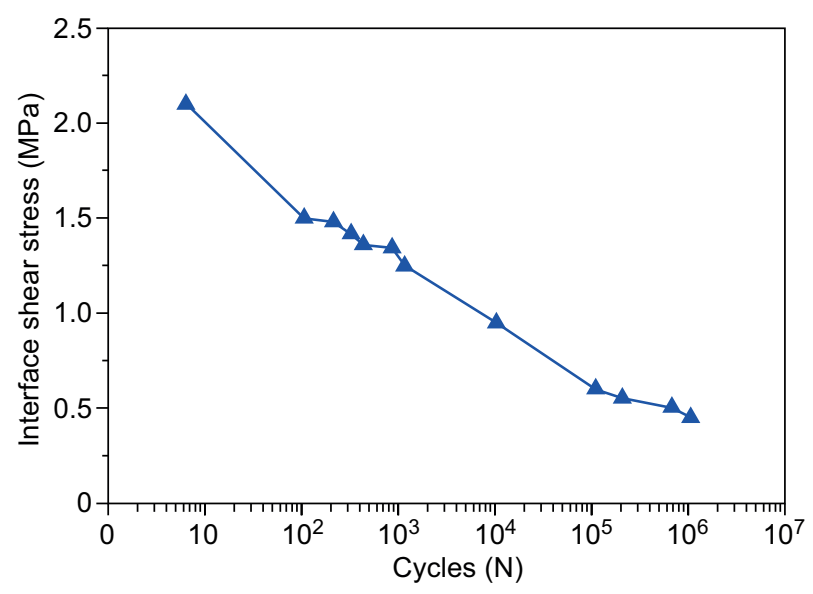

b)

Figure 21. The experimental and theoretical hysteresis dissipated energy versus the interface shear stress curves(a) and the interface shear stress versus the cycle number curve of the cross-ply SiC/MAS composite under $\sigma_{\max }=86 \mathrm{MPa}$ and the loading frequency of $10 \mathrm{~Hz}$ at $1093{ }^{\circ} \mathrm{C}$ in air (b). 
the theoretical computational values, the fibre/matrix interface shear stress corresponding to the different cycle numbers can be obtained, as shown in Figure 21b, in which the interface shear stress decreases from $2.1 \mathrm{MPa}$ at the $6^{\text {th }}$ applied cycle to $0.45 \mathrm{MPa}$ at the $1063330^{\text {th }}$ applied cycle.

\section{DISCUSSION}

The effect of loading frequency on the evolution of the interface shear stress with fatigue is shown in Figure 22. The interface shear stress at a low loading frequency is higher than that at a high loading frequency; and the interface shear stress degradation rate at a low loading frequency is higher than that at a high loading frequency.

At $566{ }^{\circ} \mathrm{C}$ in air, when the fatigue peak stress is $\sigma_{\max }=137 \mathrm{MPa}$, the fibre/matrix interface shear stress decreases from $1.2 \mathrm{MPa}$ at the $4^{\text {th }}$ applied cycle to $1 \mathrm{MPa}$ at the 230th applied cycle, and the interface shear stress degradation rate is $8.8 \times 10^{-4} \mathrm{MPa} / \mathrm{Cycle}$ with the loading frequency of $\mathrm{f}=1 \mathrm{~Hz}$; and when $f=$ $10 \mathrm{~Hz}$, the interface shear stress decreases from $1.5 \mathrm{MPa}$ at the $2^{\text {nd }}$ applied cycle to $0.8 \mathrm{MPa}$ at the $7730^{\text {th }}$ applied cycle, and the interface shear stress degradation rate is $9.0 \times 10^{-5} \mathrm{MPa} /$ Cycle, as shown in Table 1 . When the fatigue peak stress is $\sigma_{\max }=103 \mathrm{MPa}$, the interface shear stress decreases from $1 \mathrm{MPa}$ at the 4th applied cycle to $0.8 \mathrm{MPa}$ at the $920^{\text {th }}$ applied cycle, and the interface shear stress degradation rate is $2.1 \times 10^{-4} \mathrm{MPa} /$ Cycle with the loading frequency of $f=1 \mathrm{~Hz}$; and when $f=$ $10 \mathrm{~Hz}$, the interface shear stress decreases from $0.5 \mathrm{MPa}$ at the $2^{\text {nd }}$ applied cycle to $0.28 \mathrm{MPa}$ at the $572^{\text {th }}$ applied cycle, and the interface shear stress degradation rate is $3.8 \times 10^{-4} \mathrm{MPa} / \mathrm{Cycle}$, as shown in Table 1 .

At $1093{ }^{\circ} \mathrm{C}$ in air, when the fatigue peak stress is $\sigma_{\max }=103 \mathrm{MPa}$, the interface shear stress decreases from 7.6 $\mathrm{MPa}$ at the $4^{\text {th }}$ applied cycle to $1.1 \mathrm{MPa}$ at the $10608^{\text {th }}$ applied cycle, and the interface shear stress degradation rate is $6.1 \times 10^{-4} \mathrm{MPa} / \mathrm{Cycle}$; and at the loading frequency of $10 \mathrm{~Hz}$, the interface shear stress decreases from

Table 1. The interface shear stress degradation rate of the cross-ply SiC/MAS composite at $566{ }^{\circ} \mathrm{C}$ and $1093{ }^{\circ} \mathrm{C}$ in air.

\begin{tabular}{|c|c|c|c|c|c|c|c|}
\hline $\begin{array}{l}\text { Temperature } \\
\left({ }^{\circ} \mathrm{C}\right)\end{array}$ & $\begin{array}{l}\text { Loading frequency } \\
\qquad(\mathrm{Hz})\end{array}$ & $\begin{array}{c}\sigma_{\max } \\
(\mathrm{MPa})\end{array}$ & $\begin{array}{c}\tau_{\text {initial }} \\
(\mathrm{MPa})\end{array}$ & $\begin{array}{c}\tau_{\text {final }} \\
(\mathrm{MPa})\end{array}$ & $N_{\text {initial }}$ & $N_{\text {final }}$ & $\psi(\mathrm{MPa} / \mathrm{Cycle})$ \\
\hline \multirow{6}{*}{566} & \multirow{3}{*}{1} & 137 & 1.2 & 1 & 4 & 230 & $8.8 \times 10^{-4}$ \\
\hline & & 120 & 1.2 & 0.9 & 3 & 46 & $6.9 \times 10^{-3}$ \\
\hline & & 103 & 1 & 0.8 & 4 & 920 & $2.1 \times 10^{-4}$ \\
\hline & \multirow[b]{3}{*}{10} & 137 & 1.5 & 0.8 & 2 & 7730 & $9.0 \times 10^{-5}$ \\
\hline & & 120 & 0.7 & 0.25 & 6 & 6150 & $7.3 \times 10^{-5}$ \\
\hline & & 103 & 0.5 & 0.28 & 2 & 572 & $3.8 \times 10^{-4}$ \\
\hline \multirow{7}{*}{1093} & \multirow{4}{*}{1} & 137 & 9.8 & 5.6 & 4 & 25 & $2.0 \times 10^{-1}$ \\
\hline & & 120 & 8.2 & 3.6 & 3 & 76 & $6.0 \times 10^{-2}$ \\
\hline & & 103 & 7.6 & 1.1 & 4 & 10608 & $6.1 \times 10^{-4}$ \\
\hline & & 96 & 6.2 & 1 & 3 & 33300 & $1.5 \times 10^{-4}$ \\
\hline & \multirow{3}{*}{10} & 103 & 2.4 & 0.6 & 6 & 94044 & $1.9 \times 10^{-5}$ \\
\hline & & 96 & 2.1 & 0.85 & 6 & 28400 & $4.4 \times 10^{-5}$ \\
\hline & & 86 & 2.1 & 0.45 & 6 & 1063330 & $1.5 \times 10^{-6}$ \\
\hline
\end{tabular}

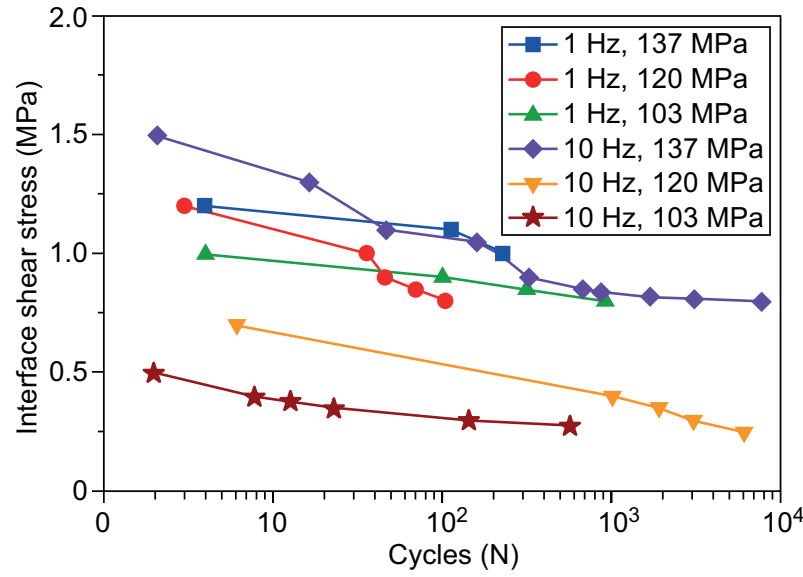

a)

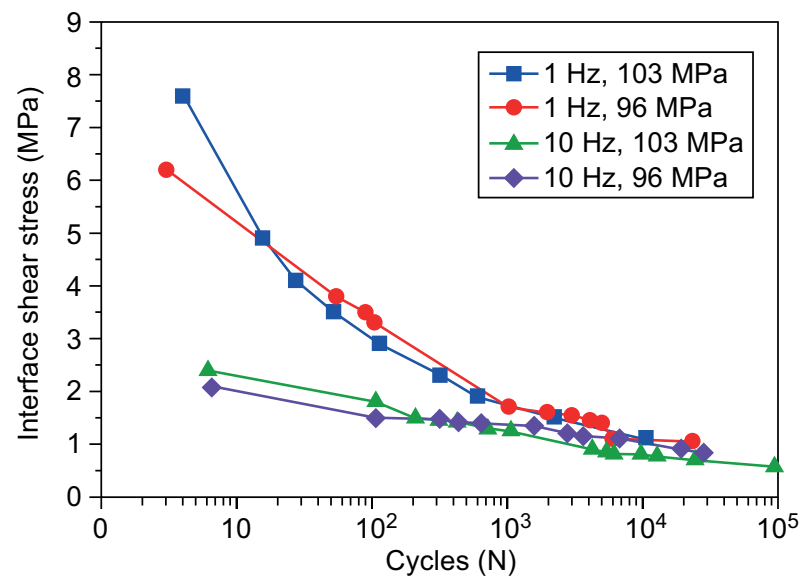

b)

Figure 22. The interface shear stress versus the cycle number curves of the cross-ply SiC/MAS composite corresponding to: a) $566^{\circ} \mathrm{C}$ in air; and b) $1093{ }^{\circ} \mathrm{C}$ in air. 
2.4 MPa at the $6^{\text {th }}$ applied cycle to $0.6 \mathrm{MPa}$ at the $94044^{\text {th }}$ applied cycle, and the interface shear stress degradation rate is $1.9 \times 10^{-5} \mathrm{MPa} / \mathrm{Cycle}$, as shown in Table 1 . When the fatigue peak stress is $\sigma_{\max }=96 \mathrm{MPa}$, the interface shear stress decreases from $6.2 \mathrm{MPa}$ at the $3^{\text {rd }}$ applied cycle to $1 \mathrm{MPa}$ at the 33300th applied cycle, and the interface shear stress degradation rate is $1.5 \times 10^{-4} \mathrm{MPa} /$ Cycle with the loading frequency of $1 \mathrm{~Hz}$; and when $f=10 \mathrm{~Hz}$, the interface shear stress decreases from 2.1 $\mathrm{MPa}$ at the $6^{\text {th }}$ applied cycle to $0.85 \mathrm{MPa}$ at the $28400^{\text {th }}$ applied cycle, and the interface shear stress degradation rate is $4.4 \times 10^{-5} \mathrm{MPa} / \mathrm{Cycle}$, as shown in Table 1.

The effect of the temperature on the evolution of the fibre/matrix interface shear stress with fatigue is shown in Figure 23. For the cross-ply SiC/MAS composite, the MAS matrix radial thermal expansion coefficient $\alpha_{\mathrm{rm}}$ is lower than the $\mathrm{SiC}$ fibre radial thermal expansion coefficient $\alpha_{\mathrm{rf}}$, i.e., $\alpha_{\mathrm{rm}}=1.2 \times 10^{-6} / \mathrm{K}$ vs. $\alpha_{\mathrm{rf}}=2.9 \times 10^{-6} / \mathrm{K}$, leading to the radial thermal residual tensile stress at the fibre/matrix interface at a testing temperature $T_{1}$ lower than the processing temperature $\mathrm{T}_{0}$, i.e., $T_{1}<T_{0}$. After the fibre/matrix interface debonding, a gap appears between the fibre and the matrix, this gap can be described using the following equation. [16]

$$
\psi=\frac{\tau_{\mathrm{i}}\left(N_{\text {initial }}\right)-\tau_{\mathrm{i}}\left(N_{\text {final }}\right)}{N_{\text {initial }}-N_{\text {final }}}
$$

This gap decreases as the testing temperature increases, leading to the increase in the interface shear stress when the testing temperature increases. At $566^{\circ} \mathrm{C}$ in air, the interface shear stress is lower than that at the testing temperature of $1093{ }^{\circ} \mathrm{C}$, as shown in Figure 23a and $\mathrm{b}$. However, the interface shear stress degradation rate also increases with the temperature, i.e., when the fatigue peak stress is $\sigma_{\max }=137 \mathrm{MPa}$ and $\mathrm{f}=1 \mathrm{~Hz}$, the interface shear stress degradation rate is $8.8 \times 10^{-4} \mathrm{MPa} /$ Cycle at $566{ }^{\circ} \mathrm{C}$ in air, and $2.0 \times 10^{-1} \mathrm{MPa} / \mathrm{Cycle}$ at $1093{ }^{\circ} \mathrm{C}$ in air.

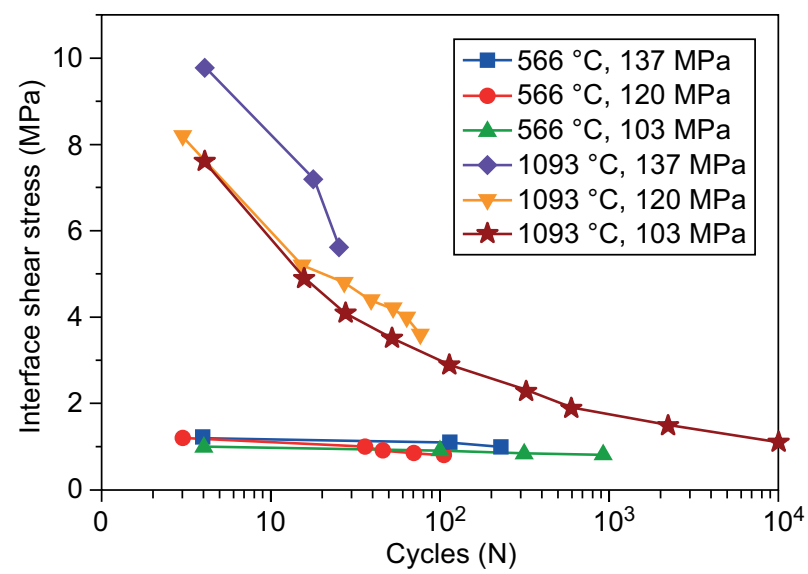

a)

\section{CONCLUSIONS}

In this paper, the synergistic effects of the loading frequency and testing temperature on the fatigue hysteresis behaviour of a cross-ply $\mathrm{SiC} / \mathrm{MAS}$ composite have been investigated. The fatigue stress-strain hysteresis loop models, considering different matrix cracking modes, were developed to establish the relationships between the hysteresis loops, hysteresis dissipated energy and interface shear stress. Comparing the experimental fatigue hysteresis dissipated energy with the theoretical computational values, the fibre/matrix interface shear stress of the cross-ply SiC/MAS corresponding to the different loading frequencies, testing temperatures, fatigue peak stresses and applied cycle numbers have been obtained.

- The experimental fatigue hysteresis dissipated energy of the cross-ply SiC/MAS decreases with the increasing cycle number, which lies in the left part of theoretical hysteresis dissipated energy versus the applied cycle number curves; and the fatigue stress-strain hysteresis loops of cross-ply SiC/MAS corresponding to the interface slip Case IV, i.e., the fibre/matrix interface completely debonding and the fibre completely sliding relative to the matrix.

- At the loading frequency of $\mathrm{f}=1 \mathrm{~Hz}$, the fibre/matrix interface shear stress and the interface shear stress degradation rate are higher than that at the high loading frequency of $10 \mathrm{~Hz}$ at $566{ }^{\circ} \mathrm{C}$ and $1093{ }^{\circ} \mathrm{C}$ in air conditions.

- At $1093{ }^{\circ} \mathrm{C}$ in air conditions, the fibre/matrix interface shear stress and the interface shear stress degradation rate are higher than that at $566{ }^{\circ} \mathrm{C}$ in air conditions when the loading frequency $f=1$ and $10 \mathrm{~Hz}$.

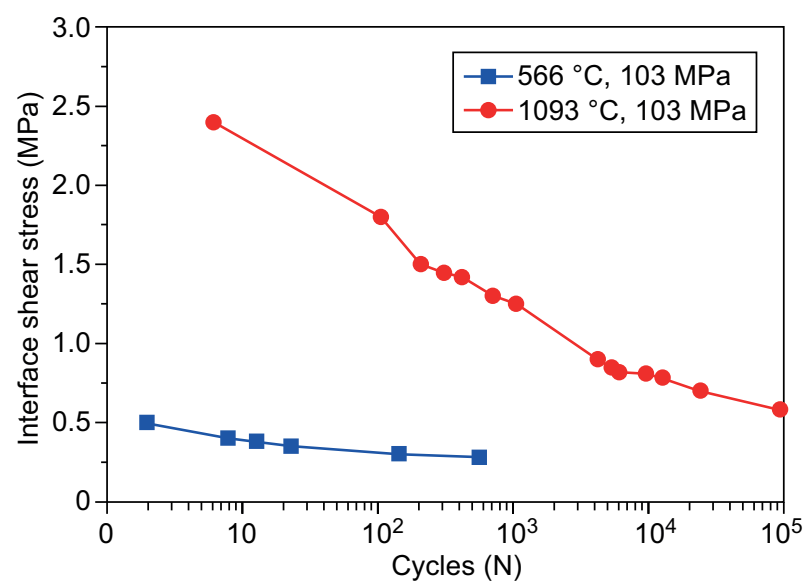

b)

Figure 23. The interface shear stress versus the cycle number curves of the cross-ply SiC/MAS composite corresponding to: a) $1 \mathrm{~Hz}$; and b) $10 \mathrm{~Hz}$. 
Acknowledgements

The work reported here is supported by the Fundamental Research Funds for the Central Universities (Grant No. NS2016070).

\section{REFERENCES}

1. R. Naslain, Design, preparation and properties of non-oxide CMCs for application in engines and nuclear reactors: an overview. Compos. Sci. Technol. 64(2004) 155-170.

2. J.W. Holmes, C.D. Cho, Experimental observations of frictional heating in fiber-reinforced ceramics. J. Am. Ceram. Soc. 75(1992) 929-938.

3. D. Rouby, P. Reynaud, Fatigue behavior related to interface modification during load cycling in ceramic-matrix fiber composites. Comps. Sci. Technol. 48(1993) 109-118.

4. A.G. Evans, F.W. Zok, R.M. McMeeking, Fatigue of ceramic matrix composites. Acta metall. mater. 43(1995) 859-875.

5. L.B. Li, Y.D. Song, Y.C. Sun, Modeling loading/unloading hysteresis behavior of unidirectional $\mathrm{C} / \mathrm{SiC}$ ceramic matrix composites. Appl. Compos. Mater. 20(2013) 655-672.

6. L.B. Li, Fatigue hysteresis behavior of unidirectional C/ $\mathrm{SiC}$ ceramic-matrix composite at room and elevated temperatures. Mater. Sci. Eng. A 625(2015) 1-18.

7. P. Reynaud, Cyclic fatigue of ceramic-matrix composites at ambient and elevated temperatures. Compos. Sci. Technol. 56(1996) 809-814.
8. A. Dalmaz, P. Reynaud, D. Rouby, G. Fantozzi, F. Abbe, Mechanical behavior and damage development during cyclic fatigue at high-temperature of a $2.5 \mathrm{D}$ carbon $/ \mathrm{SiC}$ composite. Compos. Sci. Technol. 58(1998) 693-699.

9. G. Fantozzi, P. Reynaud, Mechanical hysteresis in ceramic matrix composites. Mater. Sci. Eng. Part A. Struct. 521522(2009) 18-23.

10. L.B. Li, Y.D. Song, An approach to estimate interface shear stress of ceramic matrix composites from hysteresis loops. Appl. Compos. Mater. 17(2010) 309-328.

11. L.B. Li, Y.D. Song, Y.C. Sun, Estimate interface shear stress of unidirectional $\mathrm{C} / \mathrm{SiC}$ ceramic matrix composites from hysteresis loops. Appl. Compos. Mater. 20(2013) 693-707.

12. L.B. Li, Assessment of the interfacial properties from fatigue hysteresis loss energy in ceramic-matrix composites with different fiber preforms at room and elevated temperatures. Mater. Sci. Eng. A 613(2014) 17-36.

13. C.D. Steiner, Fatigue behavior of a cross-ply ceramic matrix composite at elevated temperatures under tensiontension loading. AFIT/GAE/ENY/94D (1994).

14. W.S. Kuo, T.W. Chou, Multiple cracking of unidirectional and cross-ply ceramic matrix composites. J. Am. Ceram. Soc. 78(1995) 745-755.

15. L.B. Li, Y.D. Song, Y.C. Sun, Effect of matrix cracking on hysteresis behavior of cross-ply ceramic matrix composites. J. Compos. Mater. 48(2014) 1505-1530.

16. P. Reynaud, D. Rouby, G. Fantozzi, Effects of temperature and of oxidation on the interfacial shear stress between fibers and matrix in ceramic-matrix composites. Acta mater. 46(1998) 2461-2469. 